\title{
Swiss Corona Stress Study: November 2021
}

Corresponding author: Dominique de Quervain (dominique.dequervain@unibas.ch)

Co-authors in alphabetical order:

Amanda Aerni

Ehssan Amini

Dorothée Bentz

David Coynel

Christiane Gerhards

Virginie Freytag

Andreas Papassotiropoulos

Nathalie Schicktanz

Thomas Schlitt

Anja Zimmer

Priska Zuber

Affiliation: University of Basel, Transfaculty Research Platform Molecular and Cognitive Neurosciences, Faculty of Psychology and Medical Faculty, Birmannsgasse 8, CH-4055 Basel, Switzerland 


\section{Abstract}

This paper reports the results of the $4^{\text {th }}$ survey of the Swiss Corona Stress Study. During the survey period from November 16-28, 2021, 11167 people from all over Switzerland participated in the anonymous online survey.

Stress factors: There were major differences between the group of vaccinated persons (58 percent of respondents) and the group of unvaccinated persons in terms of the stress factors associated with the subjective perception of stress. The greatest differences were found in the stress caused by measures such as the certificate requirement, which the majority of the unvaccinated perceived as stressful, while the majority of the vaccinated perceived it as relieving. The burden of conflicts in the family, among friends or at the workplace due to corona measures or vaccination was high among both vaccinated and unvaccinated persons. However, it was significantly higher among the latter. There were also large differences - here with a higher burden among vaccinated persons - in the fear about the health consequences of Covid-19, such as the concern that someone in the closest circle could become seriously ill. Fears of suffering from Long Covid in case of an infection, or that children might bring the coronavirus home and infect parents or grandparents, were also more prevalent among vaccinated than unvaccinated respondents. Among respondents with their own children between the ages of 4 and 11 (a total of 2079 people), only 17 percent among vaccinated parents were not at all afraid that their child will become infected with the coronavirus. Among unvaccinated parents, the figure was 68 percent.

Depressive symptoms: The proportion of respondents with moderately severe or severe depressive symptoms (PHQ>=15) was 19 percent, with vaccination status not playing a relevant role. In April 2020 (lockdown), this proportion was 9 percent; in May 2020 (partial lockdown), 12 percent; and in November 2020 (second wave), 18 percent.

Risk factors for moderately severe or severe depressive symptoms were:

- Young age: Severe depressive symptoms were most common in the youngest group (14 to 24 years old), with a share of 33 percent. Among participants who attended school or college/university, depressive symptoms were most strongly related to stress from pressure to perform at school. 
- Financial losses: Individuals whose financial reserves decreased during the pandemic were more likely to experience major depressive symptoms (32 percent) than those with unchanged or increased reserves (13 percent).

- Previous mental health issues: Individuals with mental health problems prior to the pandemic are more likely to experience major depressive symptoms (34 percent) than individuals who reported having no mental health problems prior to the pandemic (14 percent).

Substance use: Among those taking tranquilizers or sleeping pills (3544 persons), 53.6 percent reported an increase, 3.5 percent a decrease, and 42.9 percent no change in use during the pandemic (Figure 4). A similar pattern emerges for persons using nicotine, alcohol, or cannabis. The extent of use of these substances is related to the severity of stress, anxiety, and depression symptoms.

\section{Introduction}

In spring 2020 we set up the Swiss Corona Stress Study online survey to gain a better understanding of the impact of the COVID-19 pandemic on mental health (de Quervain et al., 2020a). We capture a range of demographic aspects as well as perceived stress, depression and anxiety levels. Here, we report on survey 4 that ran from November 16, 2021 until November 28, 2021, when COVID-19 infection rates were on the rise again in Switzerland. All data was collected anonymously. Our previous surveys covered the periods April 2020 (during first COVID-19 pandemic wave; Survey 1), May to June 2020 (after first COVID-19 pandemic wave; Survey 2), and November 2020 (during second COVID-19 pandemic wave Survey 3). Each survey collected data from over 10,000 participants. 


\section{Methods}

\section{Study design and participants}

We conducted a follow-up anonymous Swiss Corona Stress Study survey (Survey 4) to map the impact of the fifth COVID-19 pandemic wave on mental well-being in Switzerland. This current survey collected data between 16 and 28 November 2021 from all regions of Switzerland through referrals to the study by media reports and social media advertisement. Our previous Swiss Corona Stress Study surveys were conducted between April 6 and April 8, 2020 during the first lock-down in Switzerland, survey 2 between the May 11 and June 1, 2020 , during the partial lifting of measures, the survey 3 was run during the second upsurge of the pandemic from the November 11 until November 19, 2020.

For the current survey, participants were included if they never took part in our previous surveys, lived in Switzerland and were at least 14 years old. 11,167 participants fulfilled the inclusion criteria. No study protocol approval by the local Ethics committee was necessary, as the survey was anonymized. All participants gave prior written informed consent for participation. Participants did not receive any monetary compensation.

\section{Procedure and outcomes}

The procedure was identical to the procedure of the previous Swiss Corona Stress Study surveys. Potential participants visited a webpage, www.coronastress.ch, where they could choose one of three possible national languages, German, French or Italian. If participants were interested in taking part in the survey, they were directed to the questionnaire. The first page of the survey contained study information and informed consent. Only after agreement to the informed consent, the survey started and normally could be completed within 15 minutes. The software SoSci Survey (https://www.soscisurvey.de) was used for online assessment. Only the day of participation was recorded in SoSci Survey, while IP-addresses and timestamps were not recorded.

In the first part of the survey we collected sociodemographic and further relevant data including gender, age, nationality, country of residence, living situation, family status, religiousness, burden of childcare, highest educational level, profession, relevant pre-existing physical or psychiatric conditions, coronavirus vaccination status, coronavirus diagnostic status, potential symptoms related to the coronavirus, fears related to the 
coronavirus, acceptance of taken federal measures, burdens arising from the federal measures, changes in consumption of food / gaming / drugs / sleeping pills and tranquilizers, changes in eating and shopping routines, changed habits. Vaccinated people were additionally asked about the burden of the risk of getting sick despite being vaccinated, while unvaccinated people were asked about potential reasons for not being vaccinated. Afterwards, the following outcomes of interest were assessed: stress level, anxiety, and depressive symptoms during the two weeks immediately before the survey. Stress and anxiety levels were assessed using 6-point Likert scales ranging from 0 (not at all) to 5 (extremely strong). Depressive scores were assessed by the "Patient Health Questionnaire 9" - PHQ-9. PHQ-9 is a 9-question self-rating questionnaire to screen for the presence and severity of depression. We used the German, French and Italian translations of the PHQ-9. In addition, for participants who opted in, the survey continued with a Obsessive-Compulsive Inventory-Revised ( $\mathrm{OCl}-\mathrm{R})$ questionnaire using the German version published by (Gönner et al., 2008), and the French and Italian translations thereof. At the end of the survey, participants received automated recommendations for stress reduction on the basis of the information given in the survey, such as performing physical activities or mindfulness exercises. All questions needed to be answered in order to complete the survey. This survey also included short cognitive tests and questions about symptoms of long covid. The results of these measures will be reported separately.

\section{Statistical analyses}

Stress, anxiety and depressive symptoms of survey 4: relation to socio-demographic variables, changeable behaviors, burdens, and reliefs

We applied linear models in combination with ANOVAs for nominal variables, Pearson correlations for interval variables and Spearman's rank correlations for ordinal variables. For a first overview, the statistical models consisted of one dependent variable (one of the main outcome variables) and one independent variable. In the case of linear models, the strength of the relationships was obtained by extracting the correlation value $r$ from each corresponding linear model (i.e. normalized regression coefficient). We only report relationships with at least a small effect size $(|r| \geq 0.1)$.

These analyses we conducted separately for vaccinated and unvaccinated participants. 


\section{Comparison of stress, anxiety and depressive symptoms scores}

\section{between November 2020 and November 2021}

We compared outcomes (stress, depression and anxiety) between November 2021 (Survey 4) and November 2020 (Survey 3) by means of Wilcoxon tests. Differences exceeding a Wilcoxon effect size $|r| \geq 0.1$ were considered as significant. Comparisons were also performed after linear model adjustment of each outcome for socio-demographic factors (age, gender, education, religious belief, residency, history of prior psychiatric disorder and canton).

\section{Comparison of stress, anxiety and depressive symptoms scores \\ between vaccinated and unvaccinated participants}

We compared outcomes (stress, depression and anxiety) between participants having received at least one vaccine dose and unvaccinated participants by means of Wilcoxon tests. Differences exceeding a Wilcoxon effect size $|r| \geq 0.1$ were considered as significant. Comparisons were also performed after linear model adjustment of each outcome for socio-demographic factors (age, gender and history of prior psychiatric disorder).

\section{Identification of factors related to moderately severe and severe} depressive symptoms (PHQ-9 $\geq 15$ )

A logistic regression model was built between socio-demographic factors and the categorization of depressive symptoms into moderately severe and severe (PHQ-9 score $\geq 15$ ) and other (PHQ-9 score <15). Participants reporting gender different from male / female were excluded from this analysis as well as participants reporting unspecific household, yielding a total of $\mathrm{N}=10$ '964 participants. A first logistic regression model was built considering age, gender, education (university / not university), religious belief (believer/not believer), residency (countryside, city, agglomeration), history of prior psychiatric disorder and canton (German, French or Italian speaking). Only main effects showing significant statistical association and at least one post-hoc pairwise comparison reaching Cohen's D effect size $>|0.2|$ (square root of $\log (\mathrm{OR})^{*} 3 / \mathrm{pi}$ ) were interpreted. The effect of financial consequences (loss vs. unchanged/more) was evaluated next within this model. A second logistic regression analysis was performed considering profession (students/pupils/in 
training, job seeking, retired, in invalidity, house-wife/husband, workers in a sector financially impacted by the crisis, other workers), rather than age. Likewise, the effect of financial consequences (loss vs. unchanged/more) was next evaluated within this model.

Statistical significance of main effects was assessed by likelihood ratio test between the full model and a model discarding the variable of interest and subsequent evaluation of Nagelkerke's R2. Post-hoc pairwise comparisons between levels of each factor were performed using least-square means method as implemented in the $\mathrm{R}$ package Ismeans. Marginal effects within a given model were obtained using the ggeffect function implemented in the R package ggeffect. All confidence intervals are reported at $95 \%$ threshold.

In order to compare the magnitude of the identified effects to the effects identified in Survey 3 (November 2020), we considered logistic regression models testing for evidence of multiplicative interactions between each variable and 'time point' (November 2020, November 2021). We also tested for evidence of additive interactions (assessing differences in prevalences between groups, across time points) using binomial linear regression. These latter analyses were conducted using the $\mathrm{R}$ package blm. Predicted percentages per interaction term were obtained using the $\mathrm{R}$ predict function, under a binomial regression model considering only the interaction term of interest.

\section{Role of funding source}

The study was funded by the University of Basel. All authors had full access to all the data in the study and had final responsibility for the decision to submit for publication. None of the authors had any conflict of interest. 


\section{Results}

\section{Demographics of the study population}

A total of 11167 participants were included in our study. All participants lived in Switzerland, $87.1 \%$ had Swiss nationality. The age of the participants ranged from 14-101 (median age 41 years, mean age 41.9 years, sd 13.1). Overall, $27.1 \%$ of the participants were male, $72.1 \%$ female. $49.2 \%$ of the participants had no children, $25.2 \%$ had at least one child younger than 13 years; $40.9 \%$ had a university degree, $2.5 \%$ a doctorate, $29.8 \%$ completed an apprenticeship.

At the time of the survey $7.2 \%$ of the participants reported to be in full-time education, $1.9 \%$ to be in an apprenticeship, $5.2 \%$ to study at university and $73.9 \%$ to currently work, $2.9 \%$ to seek a job, $5.5 \%$ to receive a pension, $2.2 \%$ to receive disabled persons benefits.

Of the participants in this study, $58.2 \%$ reported to be vaccinated at least once, $50.9 \%$ vaccinated twice, $2.2 \%$ three times. $13 \%$ reported testing positive for a Corona virus infection at least once.

\section{Comparison of stress, anxiety and depressive symptoms scores between November 2020 and November 2021}

Participants reported stress levels of similar magnitude as those reported by participants during the second pandemic wave - November 2020 (de Quervain et al., 2020b) (Nov.2021: mean = 3, s.d. = 1.6; Nov.2020: mean = 2.8, s.d. = 1.7, Wilcoxon R = 0.05) (Figure 1). No difference was observed between time points in reported levels of anxiety (Nov.2021: mean $=2.0$, s.d. $=1.7$; Nov.2020: mean $=2.0$, s.d $=1.7$, Wilcoxon $R=0.001$ ). Likewise, no difference in depressive symptoms scores was observed between the two time points (Nov.2021: mean $=8.6$, s.d. $=6.3 ;$ Nov.2020: mean $=8.2$, s.d. $=6.6$, Wilcoxon $R=0.05$ ).

Similar results were observed under adjustment for socio-demographic factors (see Methods) (Stress: Wilcoxon $\mathrm{R}=0.08$; Anxiety: Wilcoxon $\mathrm{R}=0.024$; depressive symptoms score: Wilcoxon $\mathrm{R}=0.08$ ). 


\section{Comparison of stress, anxiety and depressive symptoms}

\section{scores between vaccinated and unvaccinated}

We observed slightly lower stress levels in participants having received at least one vaccination dose $(n=6499)$ as compared to unvaccinated participants (vaccinated: mean=2.8, s.d.=1.6; unvaccinated: mean=3.2, s.d. $=1.6$; Wilcoxon $R=-0.15$ ). This difference remains under adjustment for age, gender, and presence of prior psychiatric disorder (Wilcoxon $\mathrm{R}=-0.13$ ). Notably, very strong stress levels were reported for $16 \%$ of vaccinated participants as compared to $25 \%$ of unvaccinated participants.

In terms of anxiety levels or depressive symptoms scores, no difference was observed between vaccination groups that exceed at least small effect size (Wilcoxon $R<0.1$ ).

\section{Burden variables related to stress}

We identified burdens variables associated with stress levels $(|r|>0.1)$ in either vaccinated or unvaccinated participants (Figure 2). Focussing on variables associated with stress in both categories, the strongest associations were observed for burden due to conflicts in the family/friends/workplace due to coronavirus/vaccination with higher magnitude for unvaccinated (vaccinated $r=0.34$, unvaccinated $r=0.45$ ) or independent of coronavirus, with higher magnitude for vaccinated (vaccinated $r=0.27$, unvaccinated $r=0.17$ ). For both vaccinated and unvaccinated participants burdens linked to financial consequences (vaccinated $r=0.23$, unvaccinated $r=0.27$ ) or decrease in financial reserve (vaccinated $r=$ 0.20 ; unvaccinated $r=0.19$ ) were associated with stress levels. While levels of stress in vaccinated participants were globally associated with fear variables such as the fear that someone from the close circle could get seriously ill with the coronavirus $(r=0.23)$, these associations were less pronounced in unvaccinated participants (see Figure 2).

Levels of stress in unvaccinated participants were more strongly related to the burden of certificate obligation $(r=0.17)$ as compared to vaccinated participants $(r=0.11)$, whereas levels of stress for both vaccinated and unvaccinated participants correlated with burdens of restriction in personal freedom (vaccinated $r=0.20$, unvaccinated $r=0.17$ ).

Importantly, we observed strong differences in the pattern of responses between vaccinated and unvaccinated participants (see Table 1). Notably, unvaccinated participants reported independently of stress levels - overall higher burden of certificate obligation (Figure 3a), higher burden of restriction in personal freedom (Figure $3 \mathrm{~b}$ ) and lower fear that someone from the close could get seriously ill due to coronavirus (Figure $3 \mathrm{c}$ ). 
Associations between stress levels and socio-demographic factors, measures perceptions, and group specific burden and fear (e.g. school related, loneliness related) are reported in Tables $2 \& 3$ for vaccinated and unvaccinated participants respectively.

\section{Current obsessive compulsive symptoms}

We asked participants if they were suffering from more compulsions compared to before the corona crisis (e.g. washing, checking that doors are locked). This question ranged from 0 (not at all) to 5 (very strong). Increased suffering from compulsions was related to higher current stress levels $(r=0.32)$, anxiety levels $(r=0.39)$, and depressive symptoms $(r=0.46)$. Overall, $31.9 \%$ of participants reported having more obsessive compulsive symptoms (mean increase $=2.3$ units, $s d=1.3$ ). Participants reporting more obsessive symptoms had significantly more depressive symptoms (mean $=12.3, \mathrm{sd}=6.4$ ) than participants reporting an unchanged level of obsessive compulsive symptoms (mean $=6.9$, sd $=5.5$, Wilcoxon $r=$ $0.39)$.

\section{Change in consumption behavior}

We asked participants if the Covid-19 pandemic changed their consumption of specific substances / objects (from " $-5=$ much less" to "+5 much more"). Within the participants who used the specific substance/object: $53.6 \%$ reported having a higher consumption of sleeping/calming tablets than before the pandemic (less $=3.5 \%$, unchanged $=42.9 \%, \mathrm{~N}$ consumers $=3544$ ), $70.4 \%$ consumed more social media (less $=4.2 \%$, unchanged $=25.3 \%$, $\mathrm{N}$ consumers $=10854), 45.7 \%$ smoked more $($ less $=9.3 \%$, unchanged $=44.9 \%, \mathrm{~N}$ consumers $=4494), 58.4 \%$ consumed more TV (less $=6.0 \%$, unchanged $=35.6 \%, \mathrm{~N}$ consumers $=9808$ ), $54.2 \%$ played more video games (less $=4.0 \%$, unchanged $=41.8 \%, \mathrm{~N}$ consumers $=4564$ ), $36.7 \%$ consumed more cannabis (less $=6.2 \%$, unchanged $=57.2 \%, \mathrm{~N}$ consumers $=2111), 38.8 \%$ consumed more alcohol $($ less $=15.2 \%$, unchanged $=46.0 \%, \mathrm{~N}$ consumers $=8044), 16.7 \%$ consumed more other drugs $($ less $=8.3 \%$, unchanged $=75.0 \%$, $\mathrm{N}$ consumers $=1498$ ), and $26.9 \%$ eat more food (less $=7.4 \%$, unchanged $=65.7 \%, \mathrm{~N}$ consumers $=11167)$. However, shopping behavior did not change (more $=28.8 \%$, unchanged $=42.7 \%$, less $=28.8 \%, \mathrm{~N}=11167$ ).

With the exception of "other drugs", the change in consumption behavior of all these substances/objects was related to current stress level (pearson correlation: sleeping/calming tablets $=0.36$; social media $=0.30 ;$ smoking $=0.27 ; \mathrm{TV}=0.24 ;$ gaming $=0.24$; cannabis $=$ 0.20 ; alcohol $=0.19$; food $=0.16$; shopping $=0.12$ ), anxiety level (pearson correlation: sleeping/calming tablets $=0.38$; social media $=0.28$; smoking $=0.24 ; \mathrm{TV}=0.22$; gaming $=$ $0.20 ;$ cannabis $=0.14 ;$ alcohol $=0.16 ;$ food $=0.13$; shopping $=0.09$ ), and depressive 
symptoms (pearson correlation: sleeping/calming tablets $=0.46$; social media $=0.35$; smoking $=0.32 ; \mathrm{TV}=0.32 ;$ gaming $=0.32$; cannabis $=0.28$; alcohol $=0.26$; food $=0.20$; shopping $=0.17)($ see Figure 4$)$.

\section{Moderately severe and severe depressive symptoms (PHQ-9 15): Relation to socio-demographic factors}

The proportion of participants reporting clinically relevant depressive symptoms (PHQ-9 $\geq 15$ ) in this survey $(18.8 \%)$ did not significantly differ from the proportion observed in survey 3 during the second pandemic wave (November 2020: 18.4\%)(Cramer's $V<0.01$ ). The proportion of participants with clinically relevant PHQ-9 scores thus remained considerably higher than the percentage observed before the first pandemic wave $(3.4 \%$, see (de Quervain et al., 2020a)).

We examined the association of high PHQ-9 ( $(215)$ with socio-demographic factors, namely gender, age group, household (living alone, not alone), religious belief (believer, not believer), residency (city, agglomeration, countryside), education (university, not university), report of prior psychiatric disorder, Swiss canton (German speaking, Italian speaking, or French speaking)(see Methods). Profession and age group being highly overlapping, professional status was not considered in this first analysis.

Using logit regression, we observed significant overall effects of prior psychiatric disorder (Nagelkerke R2 $=5.5 \%, p=9.3 e-81)$ and age group (Nagelkerke R2 $=3.6 \%, p=6.4 e-50)$ on the prevalence of $P H Q-9 \geq 15$ depressive symptoms. Specifically, participants reporting prior psychiatric disorder showed an increased rate of moderately severe and severe depressive symptoms in survey $4(\mathrm{OR}=2.86$ [Cl:2.57-3.18]) (Figure 5-A). The prevalence of higher depressive symptoms also decreased with increasing age, with an estimated marginal prevalence of $30.8 \%$ [Cl:27.8-34\%] in individuals less than 25 years old and $4.9 \%$ [Cl:3.4-7\%] in individuals aged 65 or more (Figure $5-\mathrm{B}$ ). These effects are of comparable magnitude as those observed in survey 3, November 2020 (time inc. November 2020 and November 2021 by age and time by prior psychiatric disorder interactions $p>0.05$ )(Figure 6-A).

Unlike in survey 3 , no significant differences in prevalence of depressive symptoms was observed between Swiss cantons (time by canton interaction $p=4.3 e-03$ )(Figure 6-B).

We next considered a model accounting for loss in financial reserve during the pandemic (less vs. more-unchanged). The effect of financial reserve was significant (Nagelkerke R2 = $5.8 \%, p=6.8 \mathrm{e}-86)$, with participants reporting loss in financial reserve at higher risk than other individuals ( $\mathrm{OR}=2.82$ [Cl: 2.54-3.12]). This effect is consistent with observations from 
survey 3, with yet slightly higher magnitude as compared to November 2020 (time by finance interaction $p=3.4 \mathrm{e}-03$, financial reserve decrease in November 2020 OR $=2.28$ [2.06-2.52])(Figure 6C).

We next considered a model considering professional status (students/pupils/in training, seeking for a job, in invalidity, workers in a sector financially impacted by the crisis, other workers, housewives/husbands, retired) rather than age. Consistent with observations from survey 3 , we identified a significant effect of profession on the prevalence of clinically relevant depressive symptoms (Nagelkerke R2 $=2.7 \%, p=1.96 \mathrm{e}-35$ ), with notably lower prevalence in retired participants as compared to other groups, and higher prevalence in pupils/students (Figure 7). We also identified significantly higher prevalence in participants searching for a job (OR: 2.49 [Cl:1.72-3.60] $\mathrm{p}=7.6 \mathrm{e}-12$ ), in invalidity (OR: 1.86 [Cl:1.23-2.84], $p=2.4 \mathrm{e}-04$ ), or working in a sector financially impacted by the crisis (OR: 1.65 [Cl: 1.21-2.26] $\mathrm{p}=3.8 \mathrm{e}-05$ ) as compared to other workers (Figure 7 ).

Overall, these results suggest that similar to observations from survey 3 in November 2020, younger age and financial loss due to the pandemic are independently associated with the prevalence of moderately severe to severe depressive scores, while no effect of Swiss canton was observed in survey 4 .

\section{Burdens related to current depressive symptoms in pupils, apprentices and students of the age group 14-24 years}

As we observed the highest proportion of individuals with moderately severe or severe depressive symptoms in the youngest age group (14-24 years), we analyzed which burden factors were related to depressive symptoms in pupils-apprentices-students within this age group ( $n=621)$ (Figure 8).

The highest associations were observed for variables related to school pressure (increase in pressure to perform: $r=0.43$ ) and worries about the future (worry to get poorer education due to the pandemic: $r=0.43$ ).

Depressive symptoms were also related to burden due to conflicts in family/friends related to corona measures $(r=0.27)$ or independent of corona measures $(r=0.25)$. Consistent with observations in the entire population, within this age group, higher depressive symptoms correlated with decreased financial reserve $(r=0.26)$.

Finally, depressive symptoms were also related to the burden of personal freedom restrictions $(r=0.16)$ and fear of catching the virus $(r=0.16)$ or fear of death of a relative due to coronavirus $(r=0.11)$. 


\section{Reasons for not being vaccinated}

We asked all unvaccinated participants for their reasons not to be vaccinated, multiple answers were possible. Only a small fraction of all respondents $(1,1 \%)$ stated not having had the opportunity to get vaccinated, or having fear of injections $(6.1 \%)$. The most frequently chosen reasons for not getting vaccinated were "because I doubt the effectiveness of the vaccination" (69.4\%), "because of fear of side effects" $(56.6 \%)$, and "protest against paternalism" (34\%) see Figure 9. 


\section{Figures}

Figure 1: Stress levels by time point.

$\%$ : relative to the total number of participants within each survey. Error bars correspond to $95 \% \mathrm{Cl}$.

Stress levels per time point

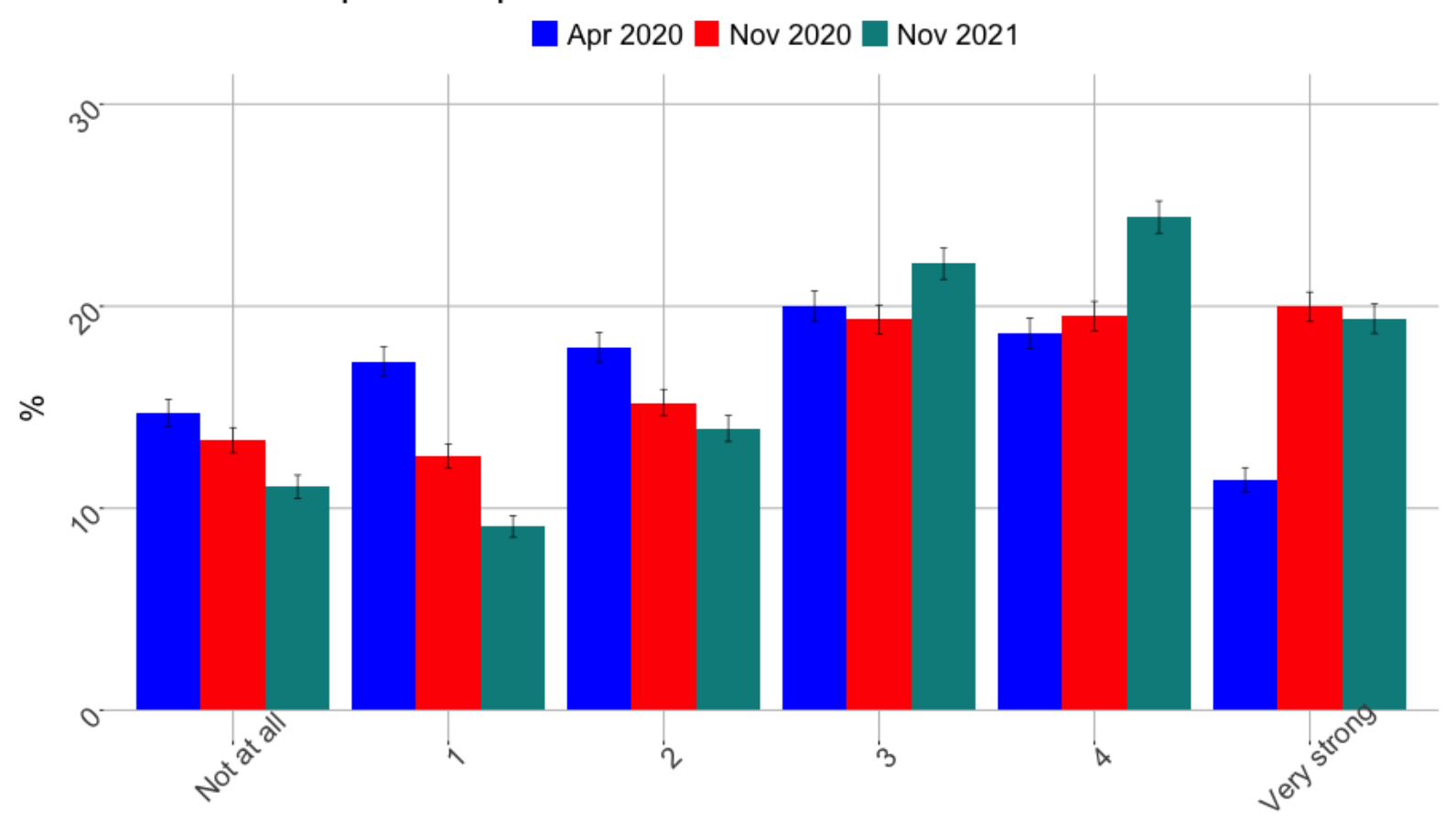




\section{Figure 2: Burdens associated with stress levels}

Burden variables linked to stress levels $(|r|>0.1)$ in either vaccinated or unvaccinated participants are reported. Dots correspond to effect size $|r|$ of association within each group. Error bars represent $95 \%$ confidence intervals of effect size.

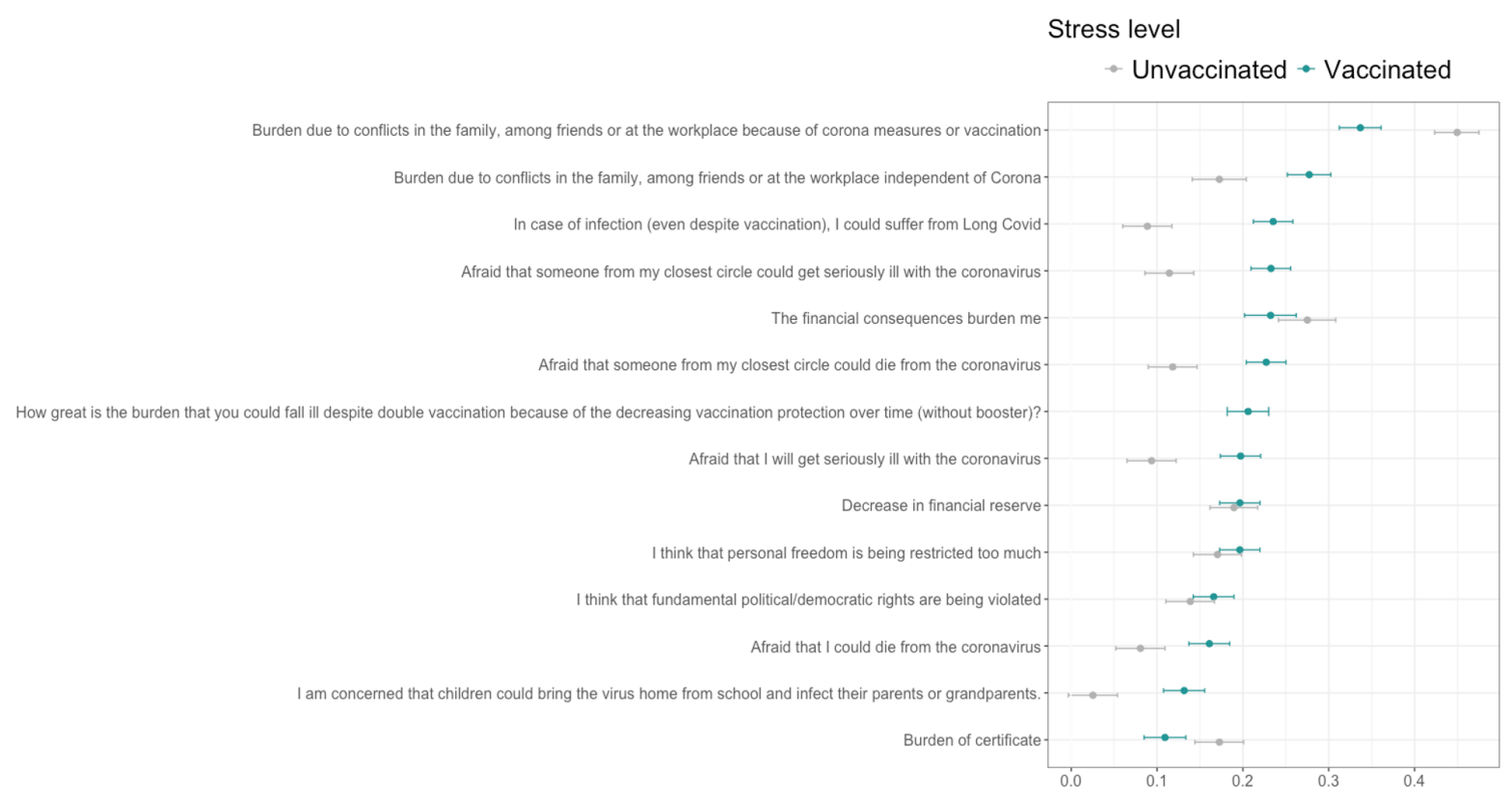


Figure 3: Comparison of response patterns between vaccinated and unvaccinated participants for burden variables.

Percentages are given relative to the total number of participants within each vaccination group. Error bars correspond to $95 \% \mathrm{Cl}$.

A:

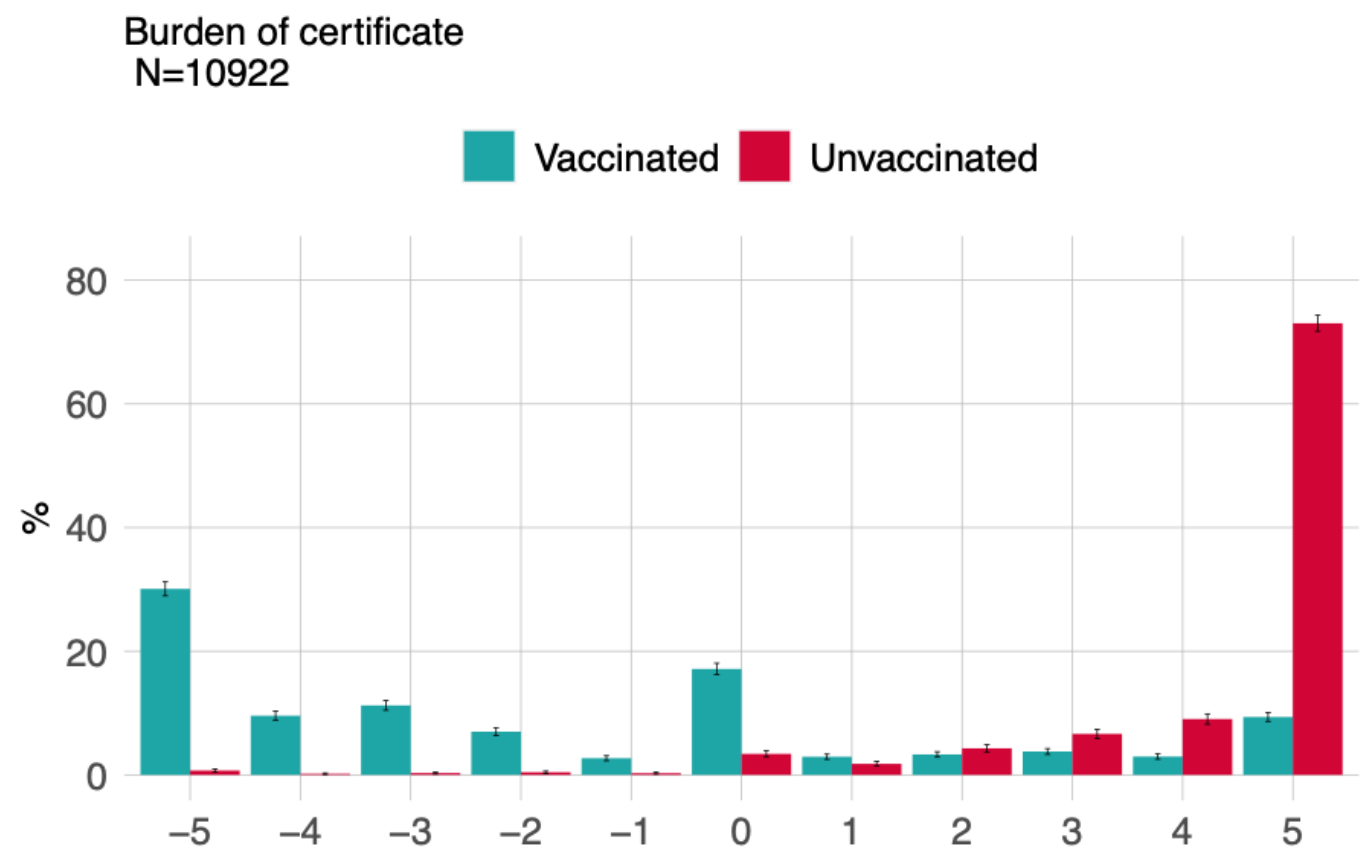

B:

I think that personal freedom is being restricted too much $\mathrm{N}=11167$

Vaccinated Unvaccinated

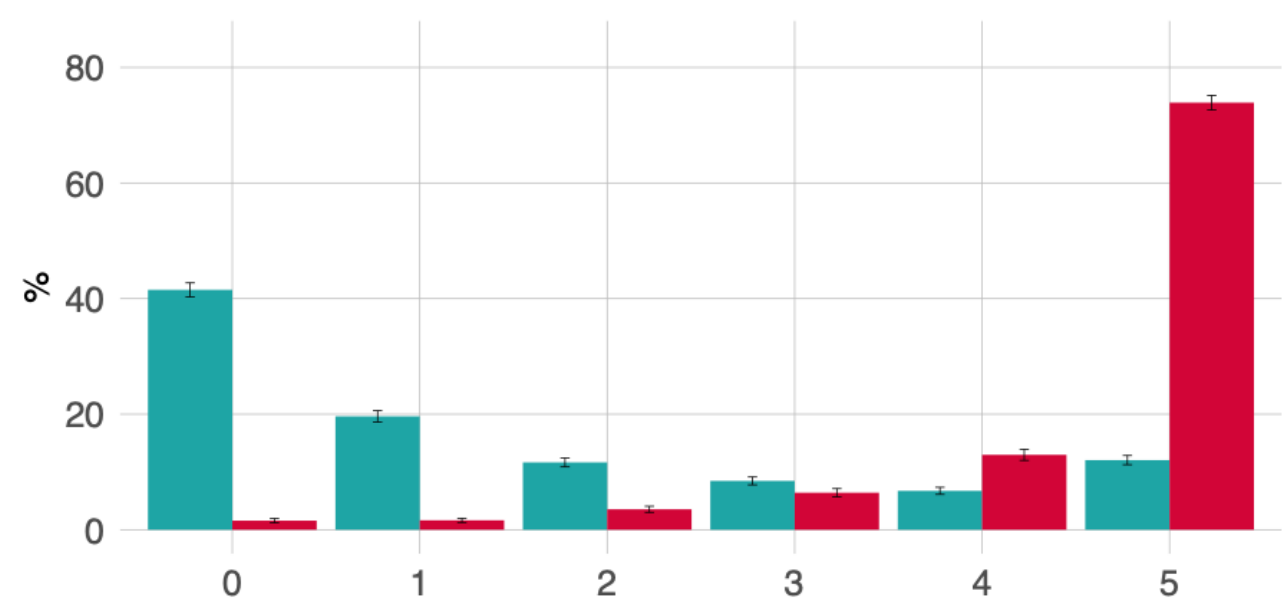


C:

Afraid that someone from my closest circle could get seriously ill with the coronavirus

$\mathrm{N}=11167$

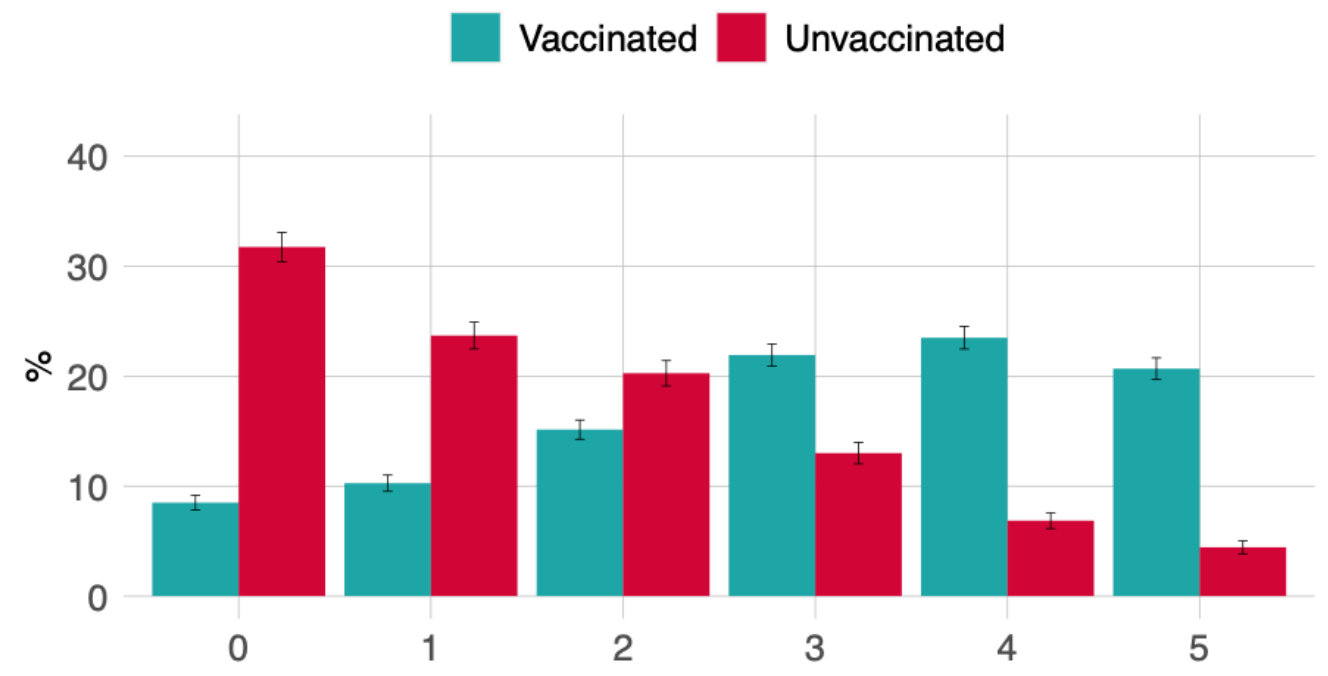




\section{Figure 4: Change of consumption behavior by stress level.}

The figure illustrates the increases in consumption of $(A)$ sleeping/calming tablets, $(B)$ in social media consumption, (C) smoking, (D) TV consumption, $(E)$ video games, $(F)$ cannabis, $(\mathrm{G})$ alcohol, $(\mathrm{H})$ other drugs, $(\mathrm{I})$ food, $(\mathrm{J})$ shopping in relation to current stress levels (colours ranging from no stress, blue $=0$ to extreme stress, light red=5). The size of the sections represent the number of participants in the respective categories

\section{A Change in consumption of sleeping/calming tablets}

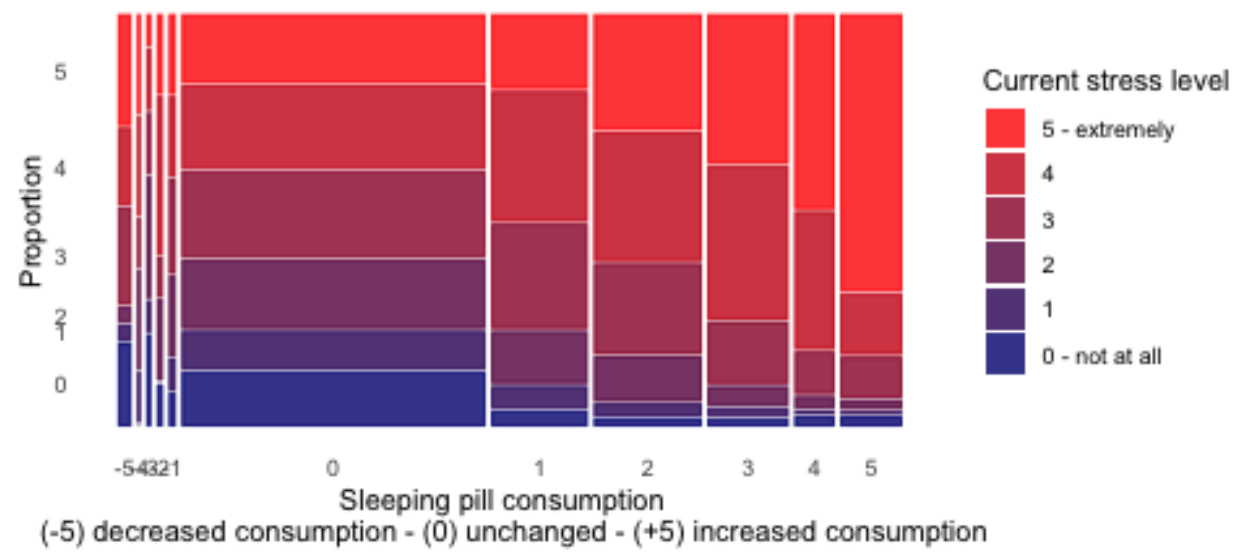

B Change in social media consumption

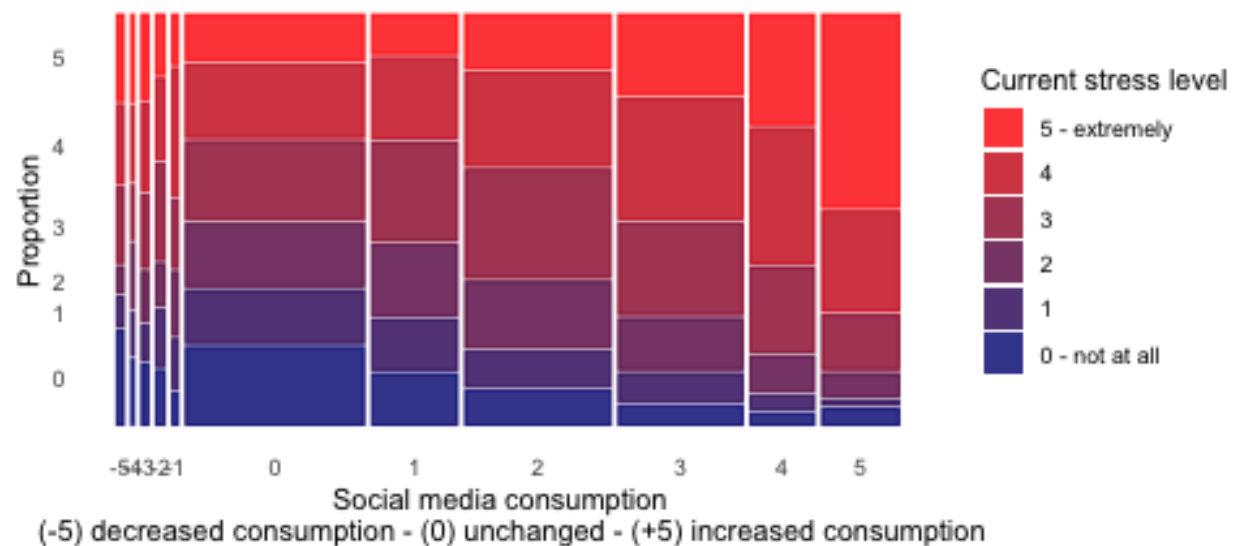




\section{Change in smoking}

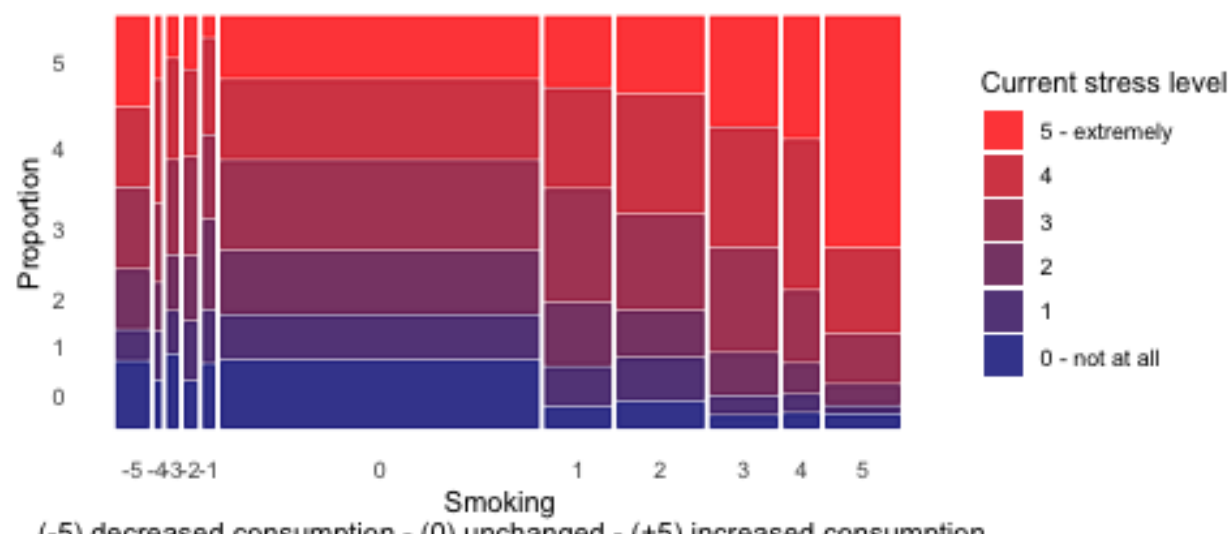

(-5) decreased consumption - (0) unchanged - (+5) increased consumption

D Change in TV consumption

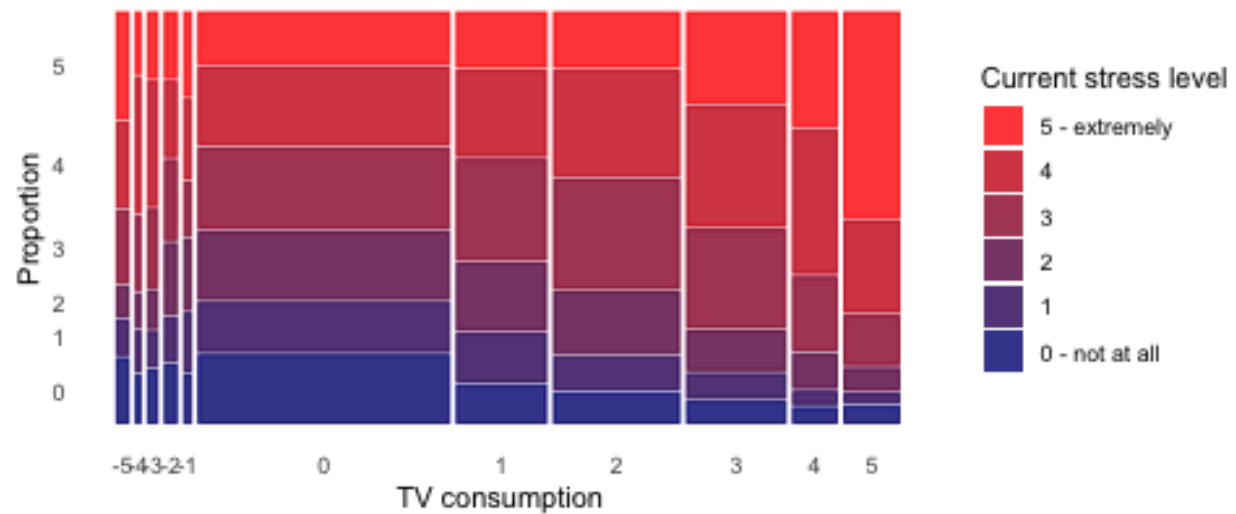

(-5) decreased consumption - (0) unchanged - (+5) increased consumption 
G Change in alcohol consumption

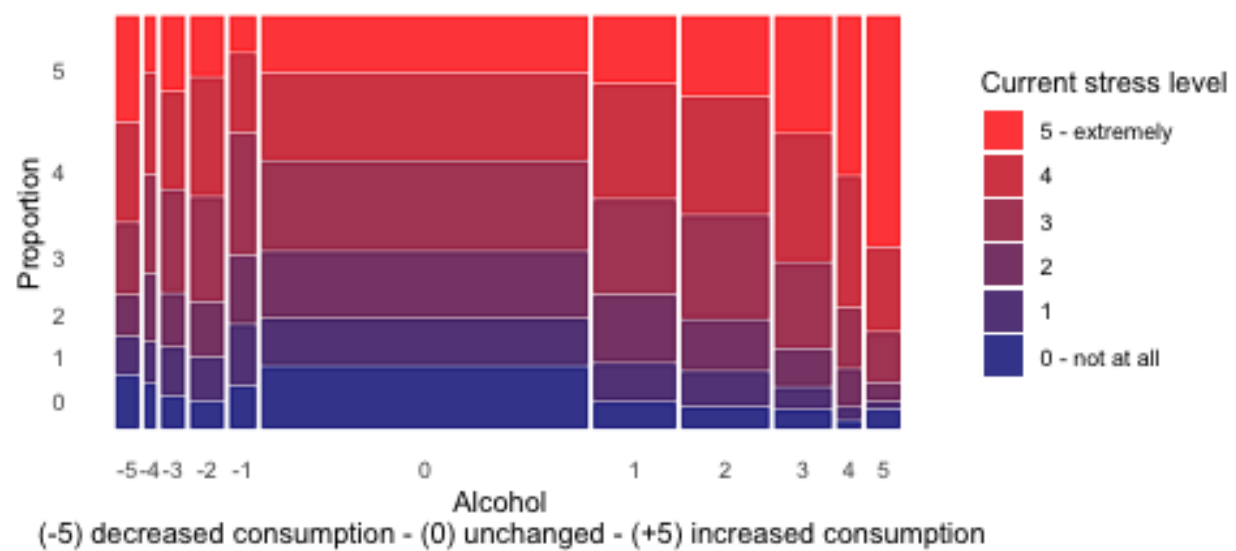

H Change in other drugs consumption

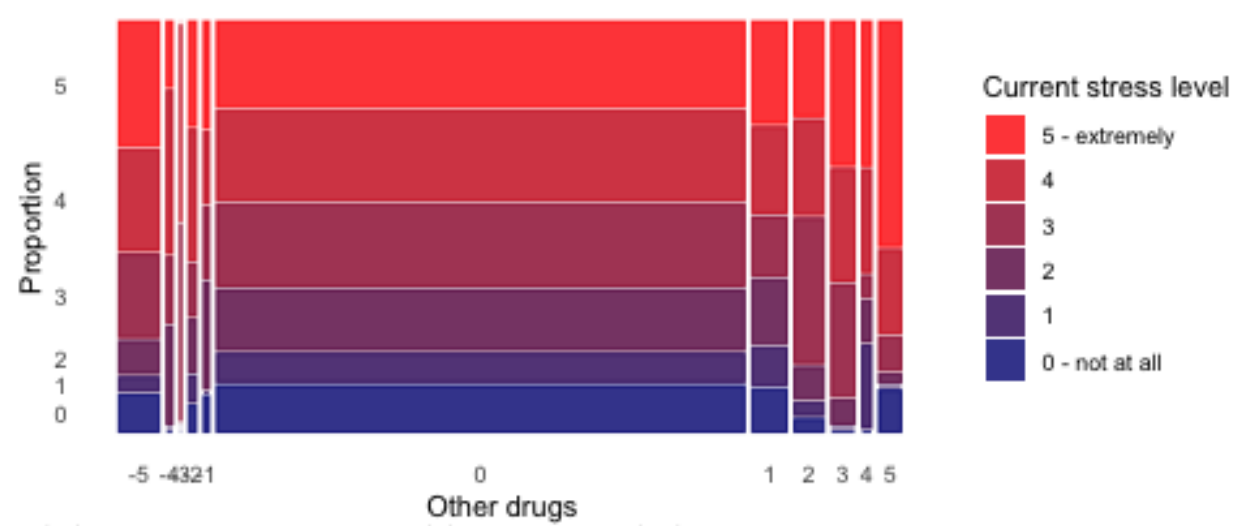

(-5) decreased consumption - (0) unchanged - (+5) increased consumption 
I Change in food consumption

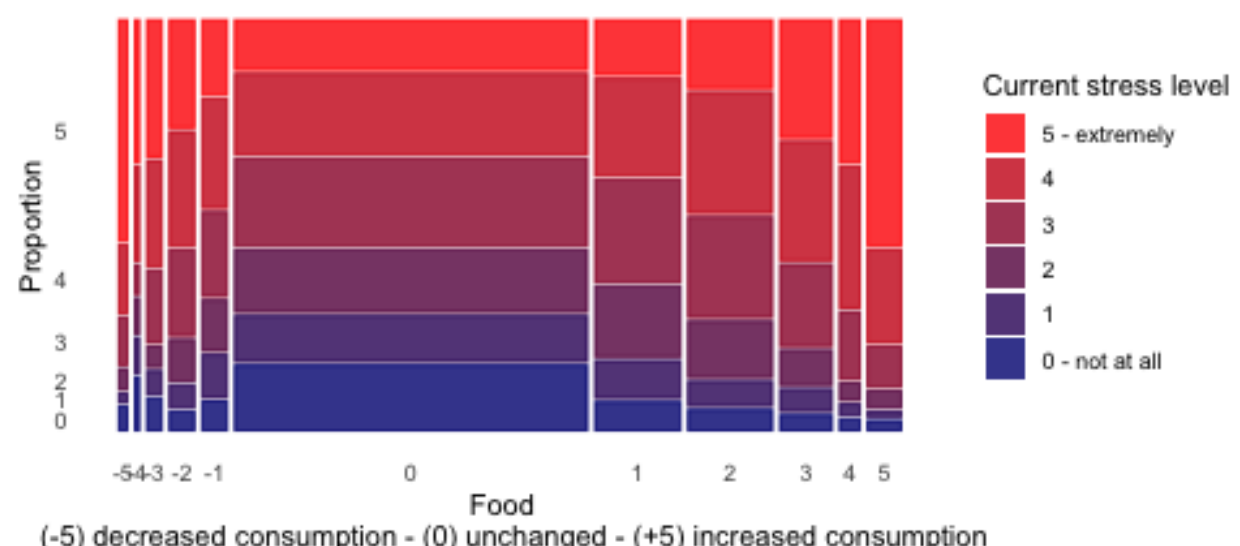

J Change in shopping consumption

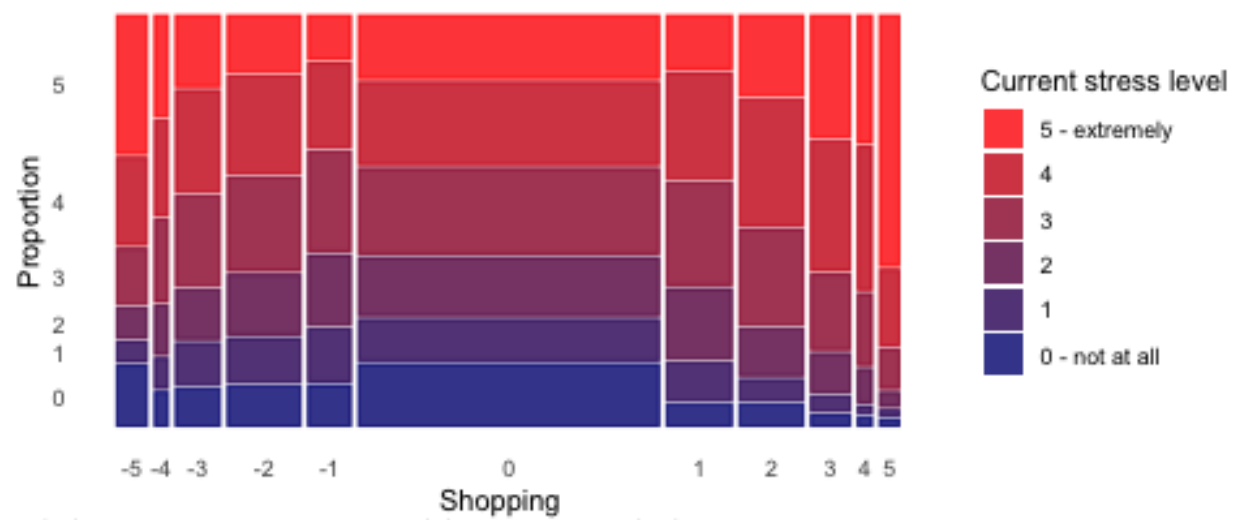

(-5) decreased consumption - (0) unchanged - (+5) increased consumption 
Figure 5: Moderately severe and severe depressive symptoms incidence in survey 4 (November 2021), by socio-demographic factors.

Estimates were obtained from LS means pairwise comparisons on Logit regression model accounting for age, gender, prior psychiatric risk, religious belief, education, canton, residency, and household. Estimates for age are shown by prior psychiatric disorder (yes/no). Error bars correspond to 95\% confidence intervals.

A:

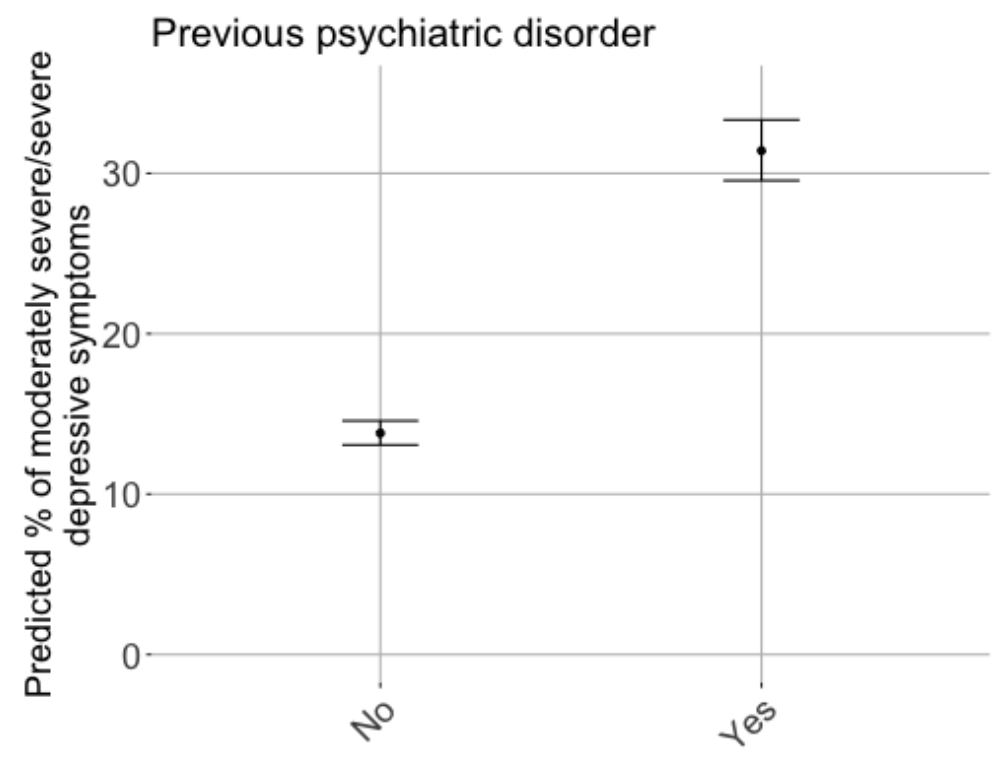

B: 
Age

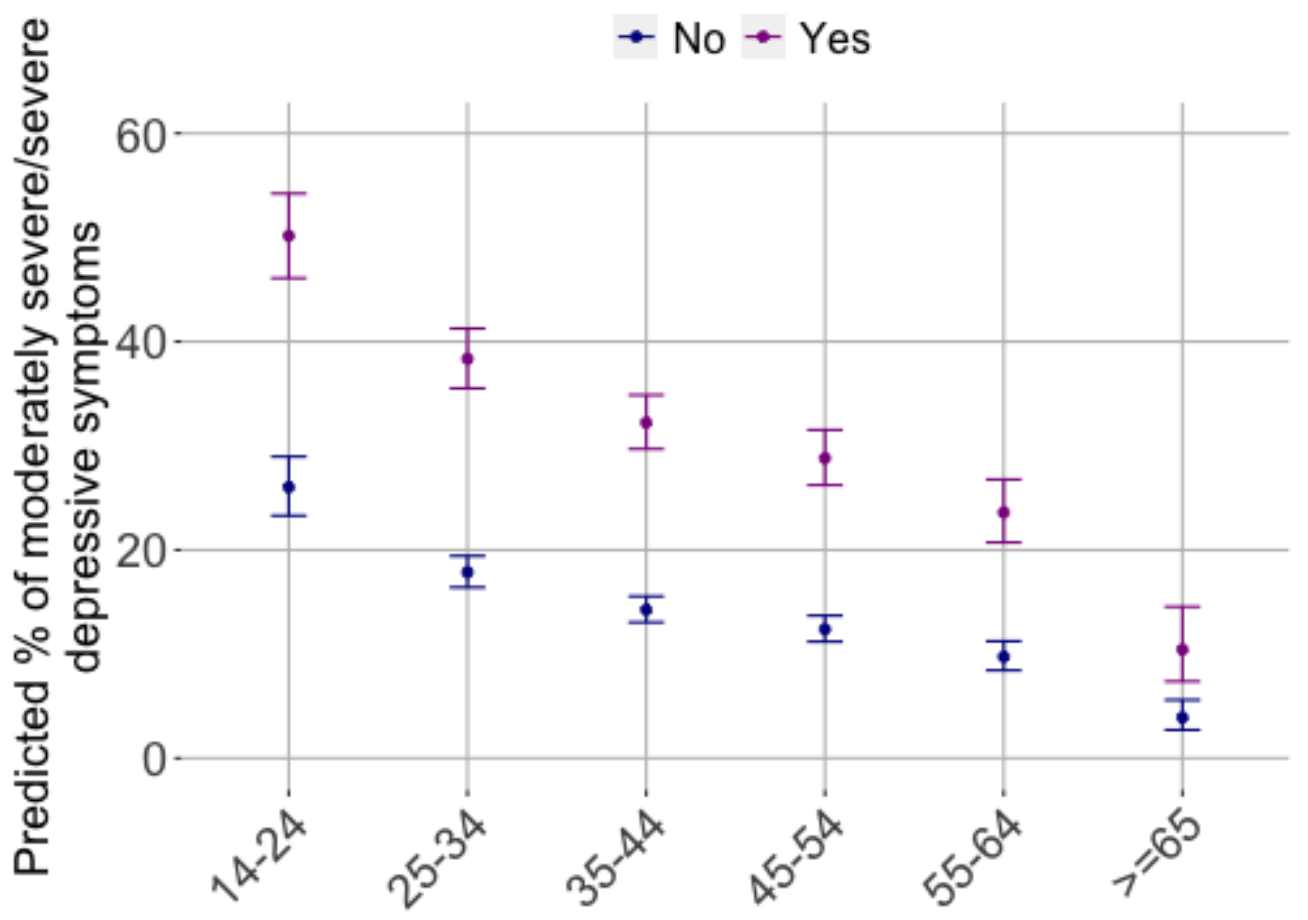




\section{Figure 6: Predicted values of moderately severe/severe depressive symptoms over time.}

Predicted values (\%) were obtained from binomial linear regression. Error bars correspond to $95 \%$ confidence interval.

A : By age group (X-axis) and report of prior psychiatric disorder (no: left; yes: right).

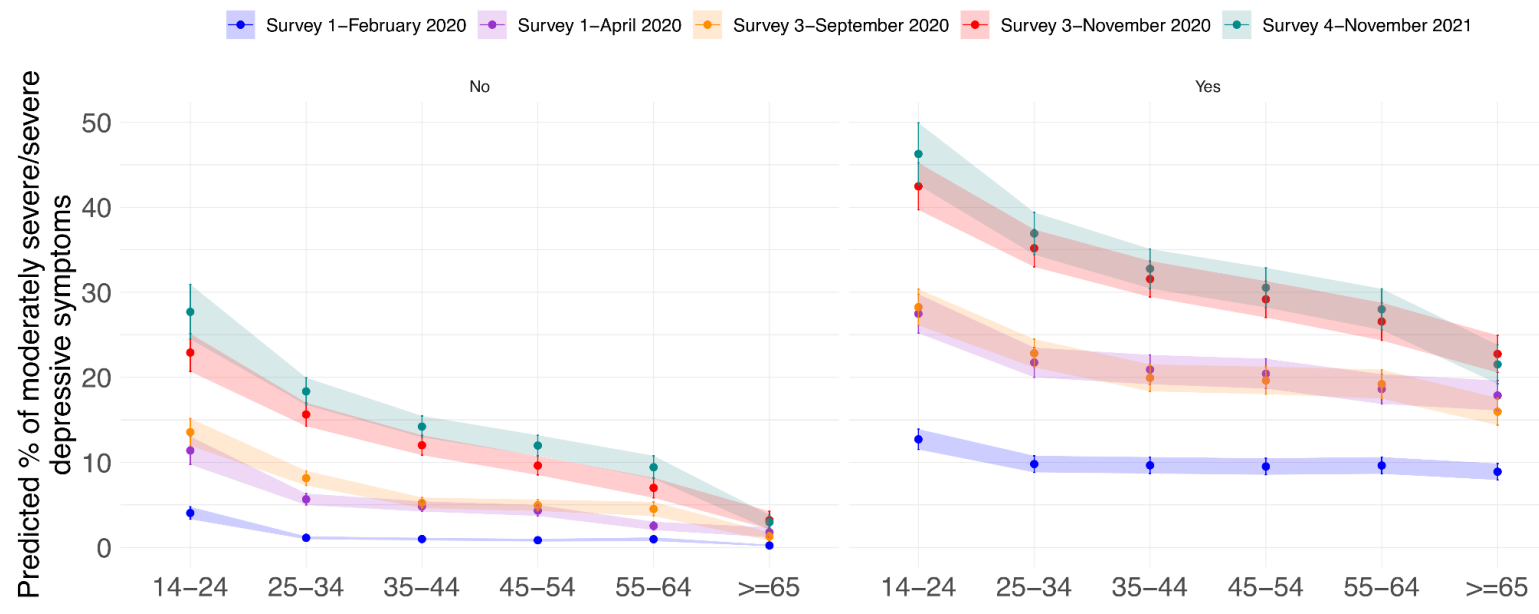

B: By canton (X-axis) and report of prior psychiatric disorder (no:left: yes: right).

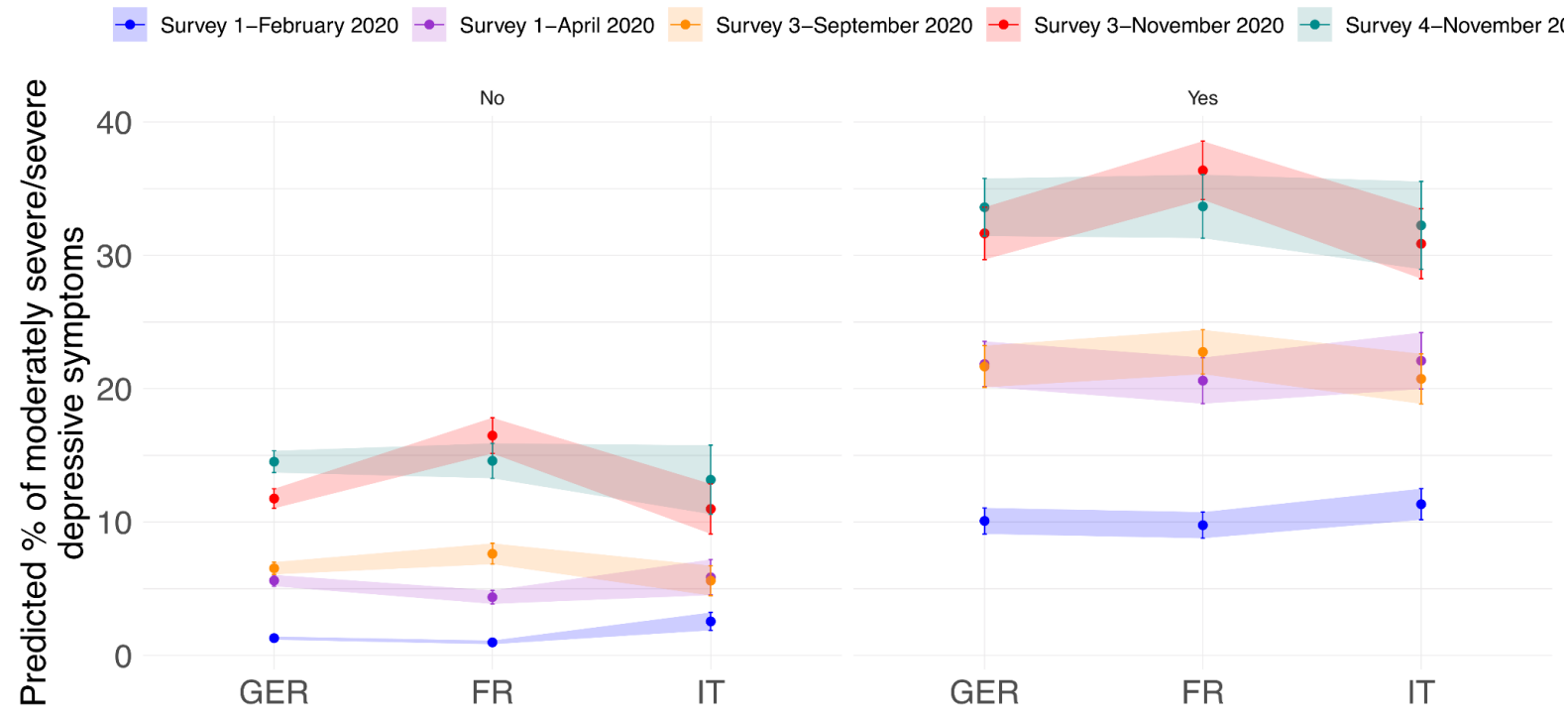


C: By financial reserve (X-axis) and report of prior psychiatric disorder (no:left: yes: right). Financial reserve data collected solely on Survey $3 \& 4$.

-- Survey 3-November 2020 -- Survey 4-November 2021

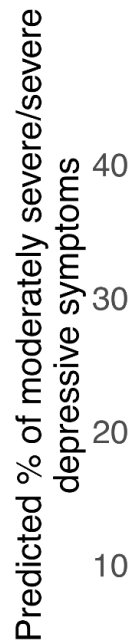

No

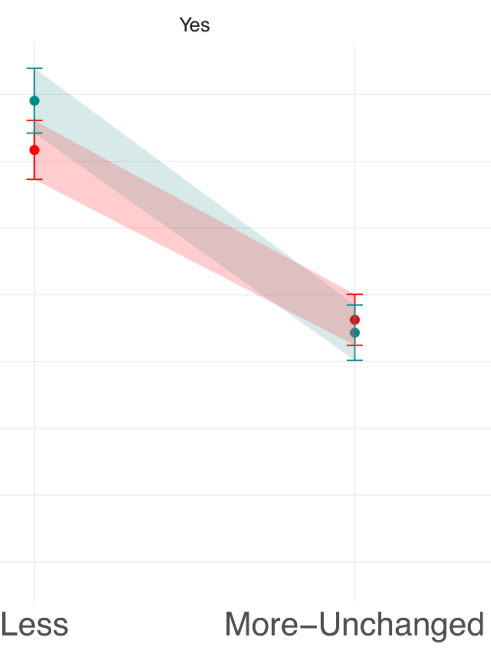

Less

More-Unchanged

Less

More-Unchanged 
Figure 7: Moderately severe and severe depression symptoms incidence in survey 4 (November 2021), by socio-demographic factors.

Estimates were obtained from LS means pairwise comparisons from Logit regression model accounting for profession, gender, prior psychiatric risk, religious belief, education, canton, residency, and household. Estimates are shown by prior psychiatric disorder (yes/no). Error bars correspond to $95 \%$ confidence intervals.

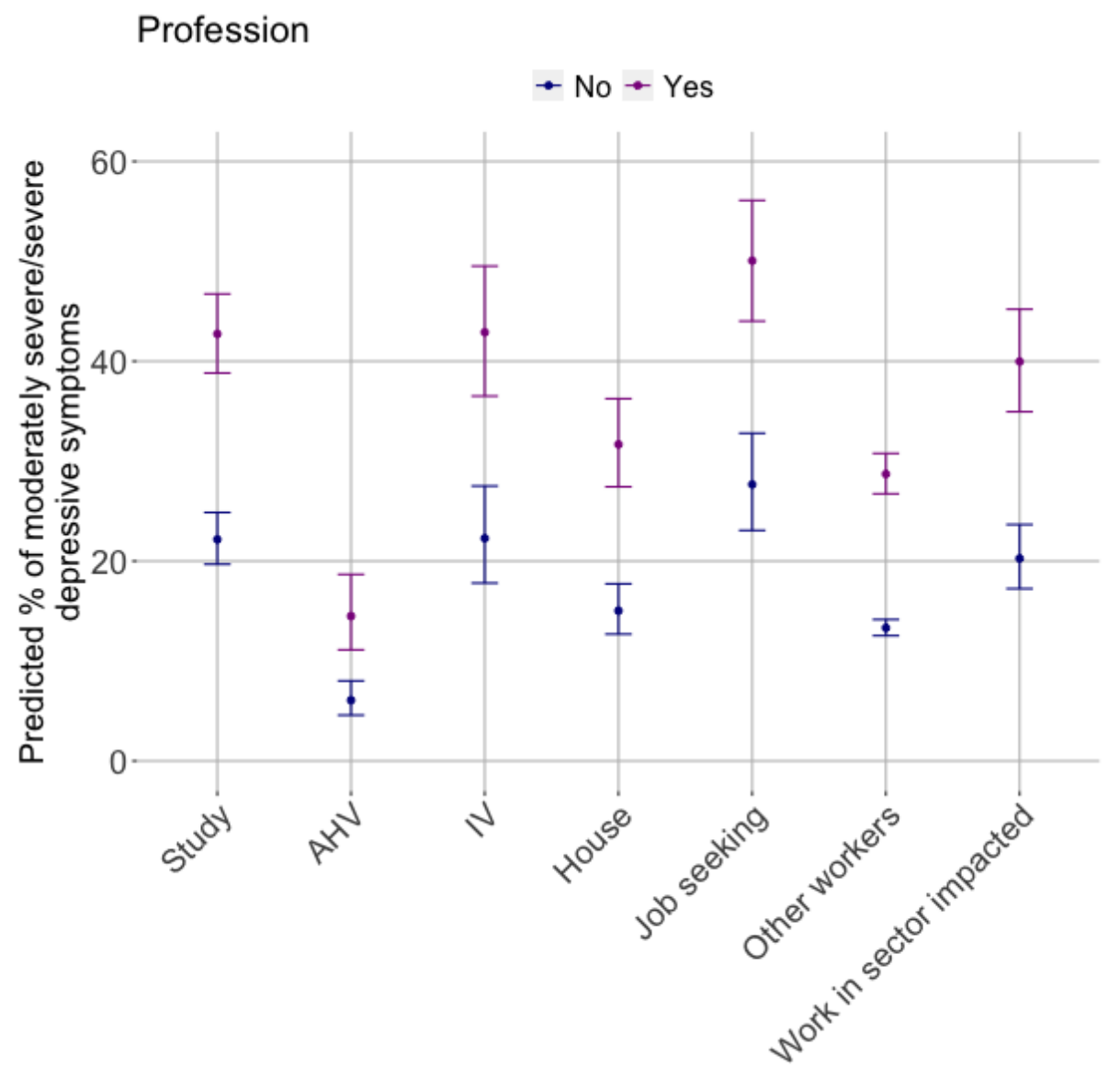


Figure 8: Burdens linked to depressive symptoms in pupils/students/apprentices within 14-24 years old.

Burden variables linked to depressive symptoms $(|r|>0.1)$ in pupils/students/apprentices aged 14-24 ( $\mathrm{N} \max =621)$. Dots correspond to effect size $|\mathrm{r}|$ of association. Error bars represent $95 \%$ confidence intervals of effect size.

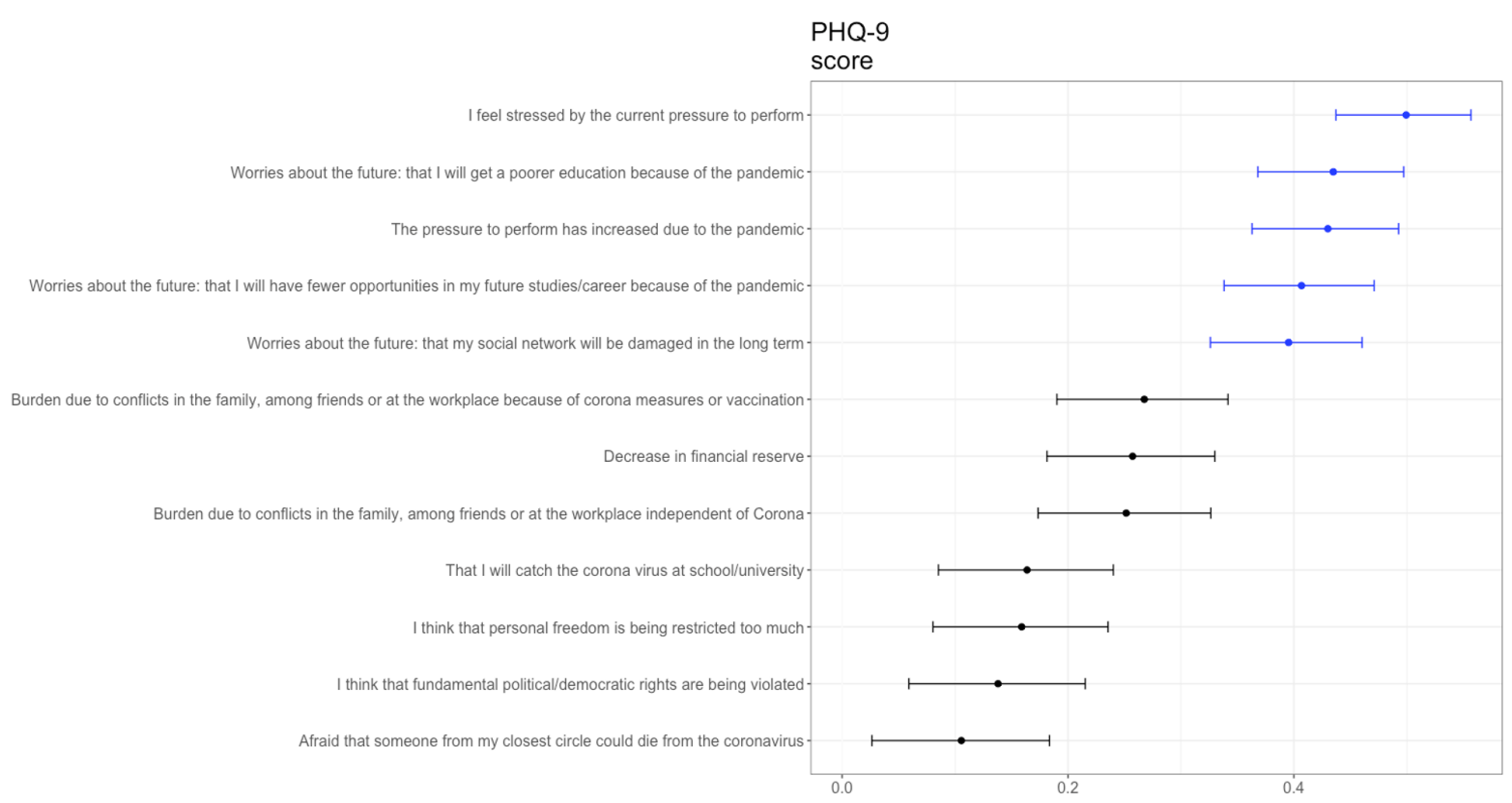




\section{Figure 9: Reasons given by unvaccinated participants for not being vaccinated}

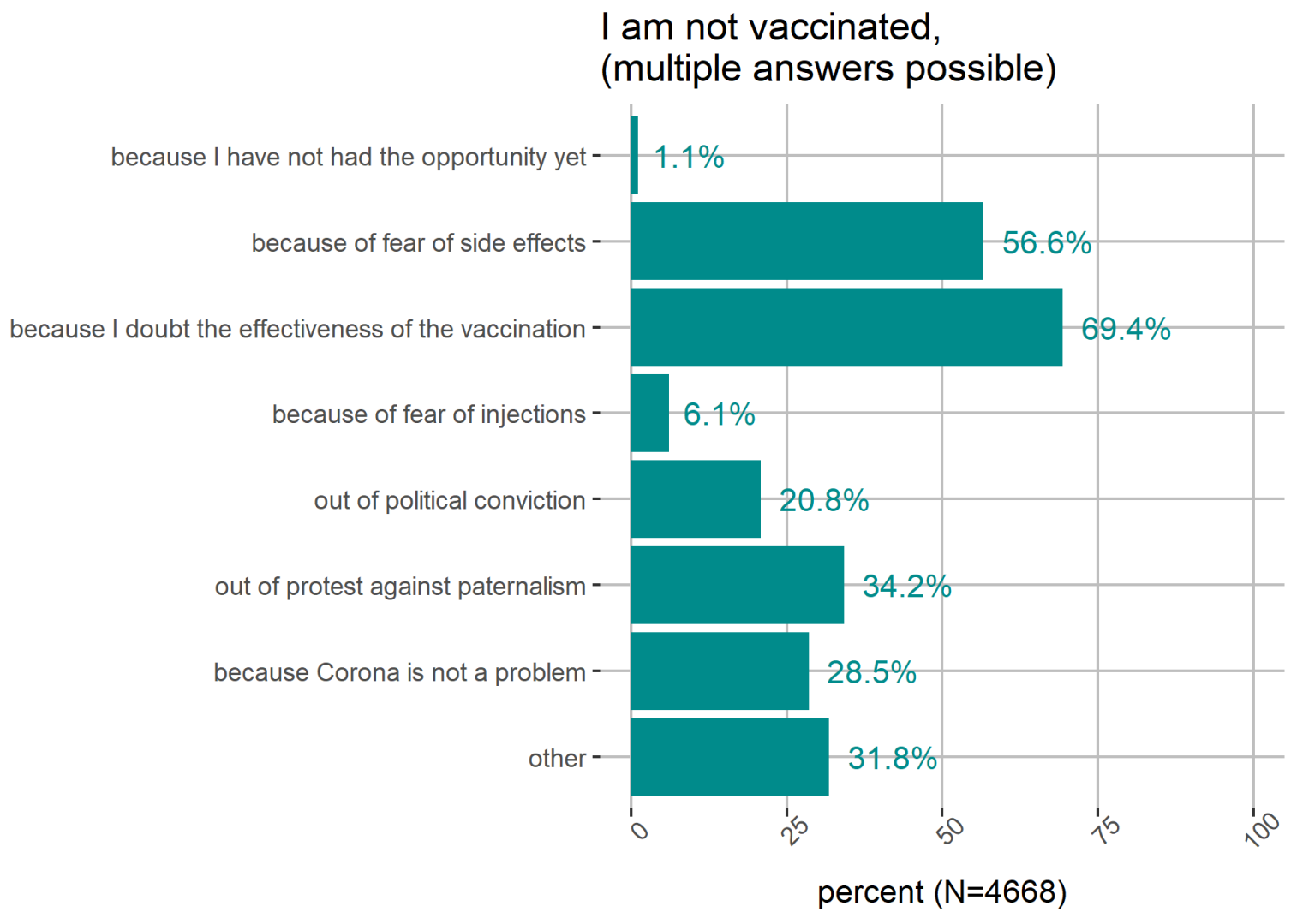




\section{Supplementary Figure S1}

This figure illustrates the incidence of COVID-19 cases in Switzerland in 2020-21 (red line, 7-day rolling average of daily new confirmed cases per million people), the proportion of the population fully vaccinated (blue dotted line) in relation to our four surveys (cyan coloured boxes). Data retrieved from ourworldindata.org on 2021/12/09 (https://github.com/owid/covid-19-data/tree/master/public/data).

\section{COVID-19 cases and vaccinations in Switzerland 2020/21}

Daily new confirmed COVID-19 cases per million people 7-day rolling average

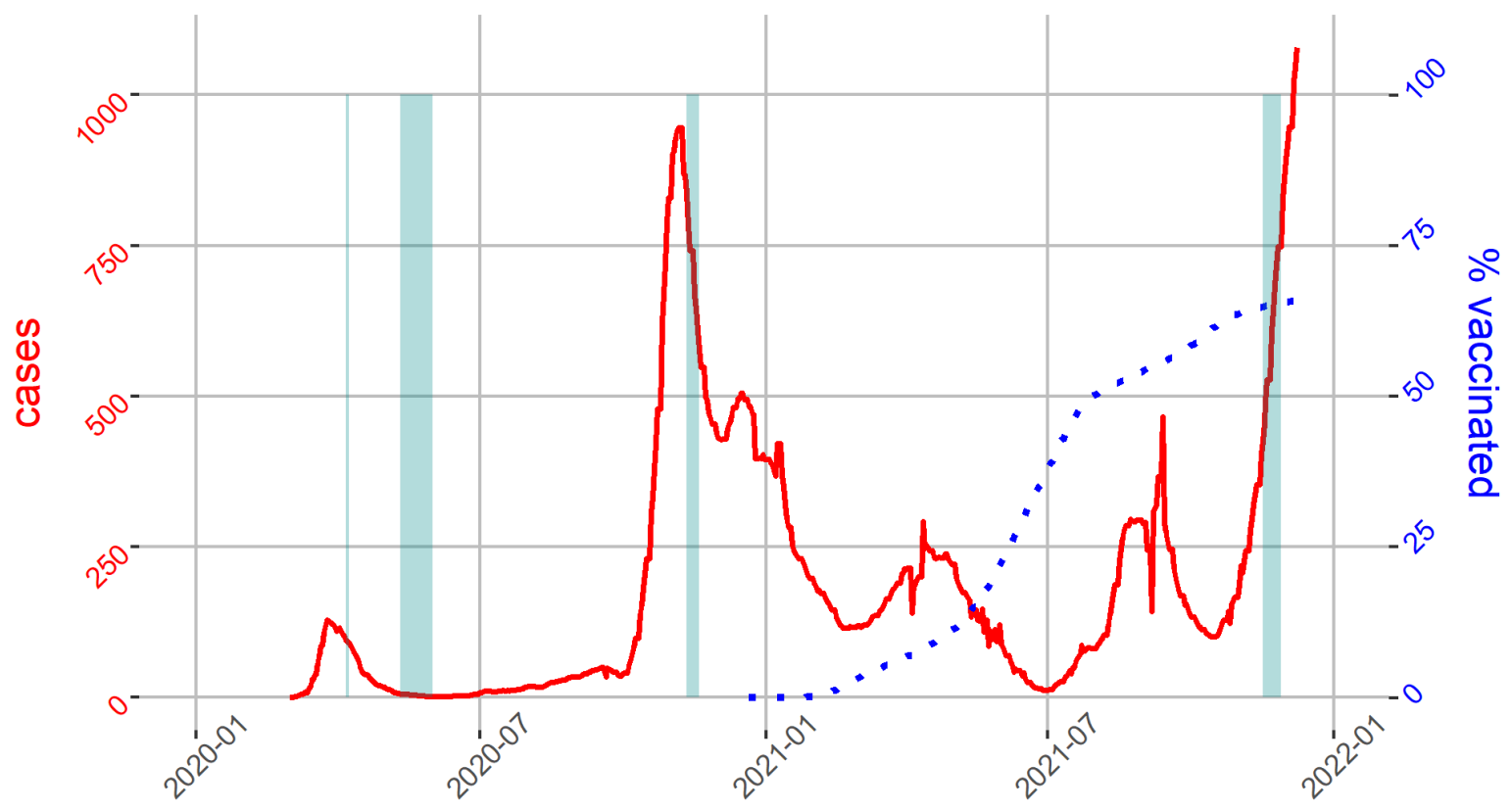

Data source: https://github.com/owid/covid-19-data/tree/master/public/data 


\section{Tables}

\section{Table 1: Comparison of response patterns between vaccinated and unvaccinated participants for burden variables.}

Variables listed by decreasing effect size.

\begin{tabular}{|c|c|c|}
\hline Question & $\mathbf{N}$ & $\begin{array}{c}\text { Cramer's } \\
\text { V }\end{array}$ \\
\hline I am concerned that the vaccination rate in Switzerland is so low. & 11167 & 0.78 \\
\hline Burden of certificate & 10922 & 0.75 \\
\hline $\begin{array}{l}\text { I think that fundamental political/democratic rights are being } \\
\text { violated }\end{array}$ & 11167 & 0.74 \\
\hline I think that personal freedom is being restricted too much & 11167 & 0.71 \\
\hline $\begin{array}{l}\text { I am concerned that my child(ren) may be infected with the } \\
\text { coronavirus }\end{array}$ & 2079 & 0.58 \\
\hline $\begin{array}{l}\text { I am concerned that people do not comply with the measures } \\
\text { (e.g. do not wear masks correctly on public transport). }\end{array}$ & 11167 & 0.58 \\
\hline $\begin{array}{l}\text { I am concerned that children could bring the virus home from } \\
\text { school and infect their parents or grandparents. }\end{array}$ & 11167 & 0.51 \\
\hline $\begin{array}{l}\text { Afraid that someone from my closest circle could get seriously ill } \\
\text { with the coronavirus }\end{array}$ & 11167 & 0.45 \\
\hline $\begin{array}{l}\text { Afraid that someone from my closest circle could die from the } \\
\text { coronavirus }\end{array}$ & 11167 & 0.42 \\
\hline Burden of mask obligation & 10954 & 0.41 \\
\hline $\begin{array}{l}\text { In case of infection (even despite vaccination), I could suffer from } \\
\text { Long Covid }\end{array}$ & 11167 & 0.41 \\
\hline Afraid that I will get seriously ill with the coronavirus & 11167 & 0.36 \\
\hline That I will catch the corona virus at school/university & 1019 & 0.33 \\
\hline The financial consequences burden me & 6801 & 0.33 \\
\hline $\begin{array}{l}\text { Burden due to conflicts in the family, among friends or at the } \\
\text { workplace because of corona measures or vaccination }\end{array}$ & 8831 & 0.31 \\
\hline
\end{tabular}


Burden due to conflicts in the family, among friends or at the workplace independent of Corona

Decrease in financial reserve 
Table 2: Variables related to current stress in vaccinated participants $(|r| \geq 0.1)$

\begin{tabular}{l|l|l|l}
\hline Meaning & $\mathbf{N}$ & $\mathbf{r}$ & $\mathbf{p}$ \\
\hline $\begin{array}{l}\text { School pressure: I feel stressed by the current } \\
\text { pressure to perform. }\end{array}$ & 605 & 0.58 & $4 \mathrm{E}-56$ \\
\hline $\begin{array}{l}\text { Worries about the future: that my social network will } \\
\text { be damaged in the long term }\end{array}$ & 605 & 0.47 & $3.48 \mathrm{E}-34$ \\
\hline I find it stressful to live alone at the moment & 1364 & 0.46 & $5.53 \mathrm{E}-71$ \\
\hline $\begin{array}{l}\text { Worries about the future: that I will get a poorer } \\
\text { education because of the pandemic }\end{array}$ & 605 & 0.41 & $2.12 \mathrm{E}-25$ \\
\hline $\begin{array}{l}\text { Worries about the future: that I will have fewer } \\
\text { opportunities in my future studies/career because of } \\
\text { the pandemic }\end{array}$ & 605 & 0.38 & $2.67 \mathrm{E}-22$ \\
\hline $\begin{array}{l}\text { School pressure: The pressure to perform has } \\
\text { increased due to the pandemic (e.g. missed } \\
\text { material due to closures, quarantine). }\end{array}$ & & & \\
\hline Change in consumption: Sleeping/calming tablets & 2098 & 0.34 & $6.39 \mathrm{E}-59$ \\
\hline $\begin{array}{l}\text { Burden due to conflicts in the family, among friends } \\
\text { or at the workplace because of corona measures or } \\
\text { vaccination }\end{array}$ & 5135 & 0.34 & $9.2 \mathrm{E}-136$ \\
\hline Age & 6499 & -0.32 & $2.3 \mathrm{E}-157$ \\
\hline Symptom last week: Fatigue & 6499 & 0.32 & $5.9 \mathrm{E}-155$ \\
\hline $\begin{array}{l}\text { Compulsions: Compared to before the corona } \\
\text { crisis, I now suffer more from compulsions (e.g. } \\
\text { washing, checking that doors are locked) }\end{array}$ & 6499 & 0.32 & $9.3 \mathrm{E}-154$ \\
\hline $\begin{array}{l}\text { Change in consumption: Social media } \\
\text { Symptom last week: Sleep problems }\end{array}$ & 6326 & 0.29 & $5.7 \mathrm{E}-123$ \\
\hline Age oldest child & 6499 & 0.29 & $2.6 \mathrm{E}-126$ \\
\hline Age youngest child & 3356 & -0.29 & $6.48 \mathrm{E}-66$ \\
\hline
\end{tabular}




\begin{tabular}{l|l|l|l}
\hline $\begin{array}{l}\text { Symptom last week: Concentration or memory } \\
\text { problems }\end{array}$ & 6499 & 0.28 & $2 \mathrm{E}-119$ \\
\hline $\begin{array}{l}\text { Burden due to conflicts in the family, among friends } \\
\text { or at the workplace independent of Corona }\end{array}$ & 5135 & 0.28 & $8.04 \mathrm{E}-91$ \\
\hline Change in consumption: Smoking & 2471 & 0.26 & $3.04 \mathrm{E}-39$ \\
\hline Symptom last week: Rapid physical exhaustion & 6499 & 0.26 & $3.31 \mathrm{E}-97$ \\
\hline Symptom last week: Headache & 6499 & 0.24 & $1.47 \mathrm{E}-83$ \\
\hline $\begin{array}{l}\text { Anxiety: In case of infection (even despite } \\
\text { vaccination), I could suffer from Long Covid }\end{array}$ & 6499 & 0.23 & $5.16 \mathrm{E}-82$ \\
\hline $\begin{array}{l}\text { Anxiety: someone from the immediate vicinity could } \\
\text { become seriously ill with the coronavirus }\end{array}$ & 6499 & 0.23 & $3.49 \mathrm{E}-80$ \\
\hline $\begin{array}{l}\text { Worries about the future: that I will catch the corona } \\
\text { virus at school/university }\end{array}$ & 605 & 0.23 & $7.84 \mathrm{E}-09$ \\
\hline $\begin{array}{l}\text { The financial consequences of the Confederation's } \\
\text { measures burden me }\end{array}$ & 3828 & 0.23 & $8.5 \mathrm{E}-48$ \\
\hline Present psychological support & 6499 & 0.23 & $1.13 \mathrm{E}-78$ \\
\hline $\begin{array}{l}\text { Anxiety: someone from the immediate vicinity could } \\
\text { die of the coronavirus }\end{array}$ & 6499 & 0.23 & $2.05 \mathrm{E}-76$ \\
\hline $\begin{array}{l}\text { I am concerned that my child(ren) may be infected } \\
\text { with the coronavirus }\end{array}$ & 1153 & 0.22 & $1.13 \mathrm{E}-14$ \\
\hline Change in consumption: television & 5893 & 0.22 & $7.94 \mathrm{E}-68$ \\
\hline $\begin{array}{l}\text { Change in consumption: Gaming/Video games } \\
\text { How great is the risk that you could fall ill despite } \\
\text { vaccination protection over time (without booster)? }\end{array}$ & 6074 & 0.21 & $5.8 \mathrm{E}-59$ \\
\hline Anxiety: I could seriously contract the Corona virus & 6499 & 0.20 & $9.5 \mathrm{E}-58$ \\
\hline $\begin{array}{l}\text { I think thancial reserves } \\
\text { freedom of movement, restrictions in social life) is } \\
\text { being restricted too much }\end{array}$ & 6499 & 0.20 & $3.15 \mathrm{E}-57$ \\
\hline
\end{tabular}




\begin{tabular}{|c|c|c|c|}
\hline Change in consumption: Food & 6499 & 0.17 & $1.14 \mathrm{E}-45$ \\
\hline Psychiatric pre-existing condition: yes / no & 6499 & 0.17 & 7.46E-45 \\
\hline Change in consumption: Cannabis & 1074 & 0.17 & 1.95E-08 \\
\hline $\begin{array}{l}\text { I think that fundamental political/democratic rights } \\
\text { are being violated }\end{array}$ & 6499 & 0.17 & $3.81 E-41$ \\
\hline Psychiatric pre-existing condition: anxiety disorder & 6499 & 0.16 & $1.5 \mathrm{E}-39$ \\
\hline Anxiety: I could die of the Corona virus & 6499 & 0.16 & $9.49 \mathrm{E}-39$ \\
\hline $\begin{array}{l}\text { For me, the Confederation is taking too few } \\
\text { measures to combat the pandemic. }\end{array}$ & 6499 & 0.16 & 2.69E-73 \\
\hline Symptom last week: Dizziness & 6499 & 0.16 & $1.84 \mathrm{E}-38$ \\
\hline Symptom last week: Muscle pain & 6499 & 0.16 & $3.08 \mathrm{E}-38$ \\
\hline Symptom last week: Gastrointestinal symptoms & 6499 & 0.16 & 4.09E-38 \\
\hline Change in consumption: Alcohol & 4770 & 0.15 & 4.6E-26 \\
\hline Gender & 6458 & 0.15 & 2.1E-33 \\
\hline Change in consumption: shopping & 6499 & 0.14 & $5.92 E-31$ \\
\hline Psychiatric pre-existing condition: Depression & 6499 & 0.14 & $1.44 \mathrm{E}-28$ \\
\hline Past psychological support & 6499 & 0.13 & 8.61E-27 \\
\hline $\begin{array}{l}\text { I am concerned that children could bring the virus } \\
\text { home from school and infect their parents or } \\
\text { grandparents. }\end{array}$ & 6499 & 0.13 & $2.4 \mathrm{E}-26$ \\
\hline $\begin{array}{l}\text { For me, the cantons take too few measures to } \\
\text { protect children from Corona in schools. }\end{array}$ & 6499 & 0.12 & 8.59E-44 \\
\hline $\begin{array}{l}\text { For me, the Confederation is taking too many } \\
\text { measures in the fight against the pandemic }\end{array}$ & 6499 & 0.12 & $4.3 \mathrm{E}-43$ \\
\hline Symptom last week: Respiratory symptoms & 6499 & 0.12 & 3.27E-22 \\
\hline Number of children & 6499 & -0.12 & 1.89E-21 \\
\hline $\begin{array}{l}\text { Burden: The certificate obligation (compared to } \\
\text { none) is for me very relieving / burdensome }\end{array}$ & 6380 & 0.11 & $2.55 \mathrm{E}-18$ \\
\hline
\end{tabular}




\begin{tabular}{l|l|l|l}
\hline $\begin{array}{l}\text { I consider the current protective measures at school } \\
\text { to be insufficient }\end{array}$ & 1153 & 0.11 & 0.000237 \\
\hline Change in consumption: Social media & 6499 & 0.10 & $7.7 \mathrm{E}-147$ \\
\hline
\end{tabular}




\section{Table 3: Variables related to current stress in not vaccinated participants $(|r| \geq 0.1)$}

\begin{tabular}{|c|c|c|c|}
\hline Meaning & $\mathbf{N}$ & $\mathbf{r}$ & $\mathbf{p}$ \\
\hline $\begin{array}{l}\text { School pressure: I feel stressed by the current pressure to } \\
\text { perform. }\end{array}$ & 414 & 0.47 & $6.0 \mathrm{E}-24$ \\
\hline $\begin{array}{l}\text { Burden due to conflicts in the family, among friends or at } \\
\text { the workplace because of corona measures or } \\
\text { vaccination }\end{array}$ & 3696 & 0.45 & $9.3 \mathrm{E}-182$ \\
\hline $\begin{array}{l}\text { Worries about the future: that I will get a poorer education } \\
\text { because of the pandemic }\end{array}$ & 414 & 0.40 & $6.3 \mathrm{E}-17$ \\
\hline I find it stressful to live alone at the moment & 972 & 0.36 & $1.2 \mathrm{E}-30$ \\
\hline Change in consumption: Sleeping/calming tablets & 1446 & 0.35 & $1.2 \mathrm{E}-43$ \\
\hline $\begin{array}{l}\text { School pressure: The pressure to perform has increased } \\
\text { due to the pandemic (e.g. missed material due to } \\
\text { closures, quarantine). }\end{array}$ & 414 & 0.33 & $3.6 \mathrm{E}-12$ \\
\hline $\begin{array}{l}\text { Compulsions: Compared to before the corona crisis, I } \\
\text { now suffer more from compulsions (e.g. washing, } \\
\text { checking that doors are locked) }\end{array}$ & 4668 & 0.31 & 2.3E-105 \\
\hline Change in consumption: Social media & 4528 & 0.30 & $9.1 \mathrm{E}-94$ \\
\hline $\begin{array}{l}\text { Worries about the future: that my social network will be } \\
\text { damaged in the long term }\end{array}$ & 414 & 0.29 & $2.2 \mathrm{E}-09$ \\
\hline $\begin{array}{l}\text { Worries about the future: that I will have fewer } \\
\text { opportunities in my future studies/career because of the } \\
\text { pandemic }\end{array}$ & 414 & 0.29 & 3.4E-09 \\
\hline $\begin{array}{l}\text { The financial consequences of the Confederation's } \\
\text { measures burden me }\end{array}$ & 2973 & 0.27 & $2.1 \mathrm{E}-52$ \\
\hline Change in consumption: Smoking & 2023 & 0.27 & 5.3E-36 \\
\hline Change in consumption: Television & 3915 & 0.27 & 3.3E-67 \\
\hline Present psychological support & 4668 & 0.25 & $5.4 \mathrm{E}-67$ \\
\hline Symptom last week: Sleep problems & 4668 & 0.25 & 2.6E-65 \\
\hline Change in consumption: Gaming/Video games & 1855 & 0.23 & $3.5 E-24$ \\
\hline
\end{tabular}




\begin{tabular}{|c|c|c|c|}
\hline Symptom last week: Fatigue & 4668 & 0.23 & $4.2 \mathrm{E}-55$ \\
\hline Age & 4668 & -0.22 & $1.2 \mathrm{E}-52$ \\
\hline $\begin{array}{l}\text { For me, the Confederation is taking too many measures } \\
\text { in the fight against the pandemic }\end{array}$ & 4668 & 0.21 & $6.9 \mathrm{E}-94$ \\
\hline Symptom last week: Concentration or memory problems & 4668 & 0.21 & $8.4 \mathrm{E}-47$ \\
\hline Change in consumption: Alcohol & 3274 & 0.20 & 4.9E-31 \\
\hline Symptom last week: Rapid physical exhaustion & 4668 & 0.19 & 4.4E-41 \\
\hline Financial reserves & 4668 & -0.19 & $1.0 \mathrm{E}-38$ \\
\hline Age oldest child & 2316 & -0.19 & 9.3E-20 \\
\hline Change in consumption: Cannabis & 1037 & 0.18 & 5.0E-09 \\
\hline Age youngest child & 2316 & -0.17 & $3.2 \mathrm{E}-17$ \\
\hline Symptom last week: Headache & 4668 & 0.17 & $1.5 \mathrm{E}-32$ \\
\hline $\begin{array}{l}\text { Burden: The certificate obligation (compared to none) is } \\
\text { for me }\end{array}$ & 4542 & 0.17 & 2.0E-31 \\
\hline $\begin{array}{l}\text { Burden due to conflicts in the family, among friends or at } \\
\text { the workplace independent of Corona }\end{array}$ & 3696 & 0.17 & 7.1E-26 \\
\hline $\begin{array}{l}\text { I think that personal freedom (e.g. restrictions on freedom } \\
\text { of movement, restrictions in social life) is being restricted } \\
\text { too much }\end{array}$ & 4668 & 0.17 & $1.8 \mathrm{E}-31$ \\
\hline Change in consumption: Food & 4668 & 0.15 & 4.6E-25 \\
\hline $\begin{array}{l}\text { I think that fundamental political/democratic rights are } \\
\text { being violated }\end{array}$ & 4668 & 0.14 & 2.7E-21 \\
\hline Gender & 4621 & 0.14 & 1.3E-20 \\
\hline Symptom last week: Gastrointestinal symptoms & 4668 & 0.13 & $1.8 \mathrm{E}-18$ \\
\hline $\begin{array}{l}\text { For me, the cantons take too many measures to protect } \\
\text { children from Corona in schools }\end{array}$ & 4668 & 0.12 & 4.4E-30 \\
\hline $\begin{array}{l}\text { Worries about the future: that I will catch the corona virus } \\
\text { at school/university }\end{array}$ & 414 & 0.12 & 1.4E-02 \\
\hline Psychiatric pre-existing condition: Yes / No & 4668 & 0.12 & 1.7E-16 \\
\hline
\end{tabular}




\begin{tabular}{l|l|l|l}
\hline $\begin{array}{l}\text { Anxiety: someone from the immediate vicinity could die of } \\
\text { the coronavirus }\end{array}$ & 4668 & 0.12 & $7.2 \mathrm{E}-16$ \\
\hline $\begin{array}{l}\text { Anxiety: someone from the immediate vicinity could } \\
\text { become seriously ill with the coronavirus }\end{array}$ & 4668 & 0.11 & $6.1 \mathrm{E}-15$ \\
\hline Change in consumption: Shopping & 4668 & 0.11 & $1.1 \mathrm{E}-14$ \\
\hline Psychiatric pre-existing condition: Depression & 4668 & 0.11 & $1.1 \mathrm{E}-13$ \\
\hline
\end{tabular}




\section{References}

Gönner, S., Leonhart, R., and Ecker, W. (2008). The Obsessive-Compulsive Inventory-Revised (OCl-R): Validation of the German version in a sample of patients with OCD, anxiety disorders, and depressive disorders. Journal of Anxiety Disorders 22, 734-749. de Quervain, D., Aerni, A., Amini, E., Bentz, D., Coynel, D., Gerhards, C., Fehlmann, B., Freytag, V., Papassotiropoulos, A., Schicktanz, N., et al. (2020a). The Swiss Corona Stress Study (OSF Preprints).

de Quervain, D., Aerni, A., Amini, E., Bentz, D., Coynel, D., Freytag, V., Gerhards, C., Papassotiropoulos, A., Schicktanz, N., Schlitt, T., et al. (2020b). The Swiss Corona Stress Study: second pandemic wave, November 2020. 